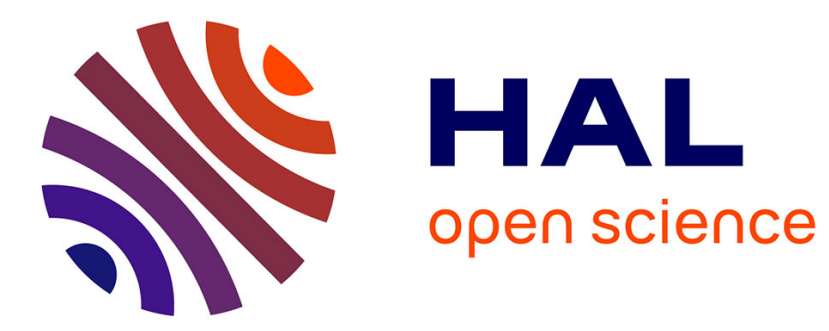

\title{
Scaling reducibility of metal oxides
}

\author{
Z. Helali, A. Jedidi, O. A. Syzgantseva, M. Calatayud, C. Minot
}

\section{To cite this version:}

Z. Helali, A. Jedidi, O. A. Syzgantseva, M. Calatayud, C. Minot. Scaling reducibility of metal oxides. Theoretical Chemistry Accounts: Theory, Computation, and Modeling, 2017, 136 (9), pp.100. 10.1007/s00214-017-2130-y . hal-01582563

\section{HAL Id: hal-01582563 https://hal.sorbonne-universite.fr/hal-01582563}

Submitted on 6 Sep 2017

HAL is a multi-disciplinary open access archive for the deposit and dissemination of scientific research documents, whether they are published or not. The documents may come from teaching and research institutions in France or abroad, or from public or private research centers.
L'archive ouverte pluridisciplinaire HAL, est destinée au dépôt et à la diffusion de documents scientifiques de niveau recherche, publiés ou non, émanant des établissements d'enseignement et de recherche français ou étrangers, des laboratoires publics ou privés. 


\section{Scaling Reducibility of Metal Oxides}

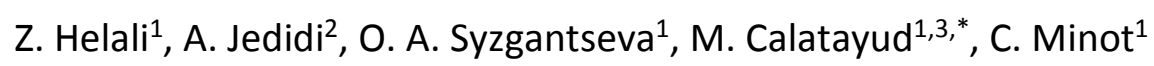

${ }^{1}$ Sorbonne Universités, UPMC Univ Paris 06, CNRS, Laboratoire de Chimie Théorique CC 137 - 4, place Jussieu, F. 75252 PARIS CEDEX 05 - France

2 Department of Chemistry, Faculty of Science, King Abdul Aziz University, Jeddah 21589, Kingdom of Saudi Arabia

${ }^{3}$ Institut Universitaire de France, F-75005, Paris, France

Corresponding author: Dr. Hab. Monica Calatayud

Sorbonne Universités, UPMC Univ Paris 06, CNRS, Laboratoire de Chimie Théorique

CC 137 - 4, place Jussieu, F. 75252 PARIS CEDEX 05 - France

e-mail : calatayu@Ict.jussieu.fr

phone : +33144272505 


\section{Abstract}

The reducibility of bulk metal oxides in which the cation is in its highest oxidation state $\left(\mathrm{MgO}, \mathrm{Sc}_{2} \mathrm{O}_{3}, \mathrm{Y}_{2} \mathrm{O}_{3}, \mathrm{TiO}_{2}, \mathrm{~m}-\mathrm{ZrO}_{2}, \mathrm{~m}-\mathrm{HfO}_{2}, \mathrm{CeO}_{2}, \mathrm{~V}_{2} \mathrm{O}_{5}, \mathrm{Nb}_{2} \mathrm{O}_{5}, \mathrm{Ta}_{2} \mathrm{O}_{5}, \mathrm{WO}_{3}, \mathrm{CrO}_{3}\right.$, $\mathrm{Al}_{2} \mathrm{O}_{3}, \beta-\mathrm{Ga}_{2} \mathrm{O}_{3}, \mathrm{SiO}_{2}, \mathrm{SnO}_{2}$ and $\mathrm{ZnO}$ ) has been studied by standard periodic density functional theory. We have defined and calculated descriptors able to describe and quantify semi-quantitatively the extent of reduction: electronic band gap, oxygen vacancy formation energy and electronic localization. We find that there is no single criterion for characterizing the reducibility. We discuss the advantages and limitations of each method, and we apply them to classify the materials with the $P B E+U$ and $B 3 L Y P$ functionals. Typical irreducible oxides such as $\mathrm{MgO}$ show a large band gap, high oxygen vacancy formation energy and electronic localization of the reduction electrons forming and F-center, with a diamagnetic singlet electronic state. Reducible oxides such as $\mathrm{TiO}_{2}$ present small band gaps, small oxygen vacancy formation energy and electron localization of the reduction electrons in the cations, decreasing their oxidation state and presenting open-shell electronic states. Intermediate or ambivalent behavior is found for $\mathrm{ZrO}_{2}, \mathrm{HfO}_{2}$, $\beta-\mathrm{Ga}_{2} \mathrm{O}_{3}, \mathrm{ZnO}$ and $\mathrm{SnO}_{2}$.

Key-words: metal oxide, rocksalt $\mathrm{MgO}, \mathrm{Sc}_{2} \mathrm{O}_{3}, \mathrm{Y}_{2} \mathrm{O}_{3}, \mathrm{TiO}_{2}$, rutile, anatase, $\mathrm{m}-\mathrm{ZrO}_{2}, \mathrm{~m}-\mathrm{HfO}_{2}$, $\mathrm{CeO}_{2}, \mathrm{~V}_{2} \mathrm{O}_{5}, \mathrm{Nb}_{2} \mathrm{O}_{5}, \mathrm{Ta}_{2} \mathrm{O}_{5}, \mathrm{WO}_{3}, \mathrm{CrO}_{3}, \mathrm{Al}_{2} \mathrm{O}_{3}, \beta-\mathrm{Ga}_{2} \mathrm{O}_{3}, \mathrm{SiO}_{2}, \mathrm{SnO}_{2}$ and $\mathrm{ZnO}$, oxygen vacancy formation, F-center, electron localization, reducibility, B3LYP, PBE+U 


\section{1) Introduction}

\section{$\underline{1.1 \text { General comments }}$}

The family of metal oxides exhibits a wide range of compositions and properties, attracting nowadays much attention due to the broad domain of industrial and technological applications. Metal oxides are highly versatile and one can find for instance metal oxides acting as insulators, semiconductors, conductors and superconductors. In particular, reducibility is a key property determining the oxide chemical behavior. The ability of metal cations to decrease their oxidation state strongly influences the physico-chemical properties of the material. The control of the material's composition, the oxidation state of its cation(s) and the extent of reduction are challenging issues to design systems with tailored structural and electronic properties. In this context, understanding the nature and the mechanisms of reduction of metal oxides is a crucial step. The aim of the present paper is to provide insights in the comprehension of reducibility mechanisms of selected metal oxides, aiming at rationalizing the stabilization of reduced systems by means of standard modeling techniques. We will use periodic density functional (DFT) methods to describe a series of representative metal oxides, $\mathrm{MgO}, \mathrm{Sc}_{2} \mathrm{O}_{3}, \mathrm{Y}_{2} \mathrm{O}_{3}, \mathrm{TiO}_{2}, \mathrm{~m}-\mathrm{ZrO}_{2}, \mathrm{~m}-\mathrm{HfO}_{2}, \mathrm{CeO}_{2}, \mathrm{~V}_{2} \mathrm{O}_{5}, \mathrm{Nb}_{2} \mathrm{O}_{5}$, $\mathrm{Ta}_{2} \mathrm{O}_{5}, \mathrm{WO}_{3}, \mathrm{CrO}_{3}, \mathrm{Al}_{2} \mathrm{O}_{3}, \beta-\mathrm{Ga}_{2} \mathrm{O}_{3}, \mathrm{SiO}_{2}, \mathrm{SnO}_{2}$ and $\mathrm{ZnO}$, as regards their reducible properties. We will present some descriptors used to measure and characterize their reducibility, and we will discuss their advantages and limitations. We will give a classification of the metal oxides based on these criteria, and we will show that there is no universal ranking or index. Besides the reducible or irreducible behavior character of common oxides ( $\mathrm{MgO}$ and $\mathrm{SiO}_{2}$ are irreducible, $\mathrm{CeO}_{2}$ or $\mathrm{TiO}_{2}$ are reducible), the intermediate character of other oxides $\left(\mathrm{ZrO}_{2}, \mathrm{Ga}_{2} \mathrm{O}_{3}\right)$ shows up upon consideration of several descriptors. 
Metal oxides are complex in their composition and structure, and we have restricted our study to binary systems whose cations are in its highest oxidation state (MO-HOS) and deprived of valence electrons. This allows a comparison of materials on an equal footing. Common metal oxides such as $\mathrm{MgO}, \mathrm{SiO}_{2}$ or $\mathrm{Al}_{2} \mathrm{O}_{3}$, for which much information is available, are naturally included in the study. As regards the transition metals series, we have focused on early ( $\mathrm{Sc}, \mathrm{Ti}, \mathrm{V}, \mathrm{Cr}$ and elements in their column in the periodic table), and late metals ( $\mathrm{Zn}$ ) whose geometry and electronic structure is well-known, avoiding systems whose cations have $\mathrm{d}$ electrons implying complex magnetic structures poorly described by standard DFT methods. Less well-known metals such as Ga, for which some data are available, are also included. The final choice of systems, although necessarily subjective, has been carefully made to give an overall view of different reducible properties and is well suited for the present work. Our goal is three-fold: i) to present and analyze reactivity descriptors able to account for the reducibility properties of metal oxides, qualitative and quantitative ii) to apply this analysis to a series of selected oxides, with both an individual description for each compound and a general classification of all the oxides family iii) to discuss the validity and drawbacks of each descriptor and the limits of using only one of them, especially in the cases of intermediate reducible behavior. The present work does not aim at i) investigating systematically all the metal oxides existing in nature ii) providing highly accurate description of structural and electronic properties of metal oxides; we limit ourselves to the use of standard $a b$ initio techniques, warning when the method is known to fail and providing alternatives when possible iii) to review all the literature of modeling metal oxides. Within this scheme, we hope that the present paper will contribute to a better understanding of the metal oxides reducibility and will provide useful information on the description of metal oxides structures by standard computational approaches. 
A final remark concerns the reactivity of metal oxide surfaces as compared to bulk materials. Our group has a long tradition in the study of surface reactivity for heterogeneous catalysis applications, in which metal oxides are of key importance. This expertise has motivated in the past the study of catalytic activity and selectivity in metal oxide surfaces as determined by the nature of the surface active sites and their interaction with gas-phase molecules. Reducibility was found to be crucial in the comprehension of the adsorption mechanisms, since it monitors both the strength and the site of the adsorption $[1,2]$. A remarkable observation is the so-called support effect, in which the supported metal oxide catalysts exhibited differences in activity of several orders of magnitude when, for the same active phase $\mathrm{V}_{2} \mathrm{O}_{5}$, the support changes from irreducible $\left(\mathrm{SiO}_{2}, \mathrm{Al}_{2} \mathrm{O}_{3}\right)$ to reducible $\left(\mathrm{TiO}_{2}\right.$, $\left.\mathrm{CeO}_{2}\right)$ oxides [3-5]. The reducibility also correlates with the "Strong Metal-support Interaction" monitoring the catalytic activity of supported metals: no SMSI effect is found for $\mathrm{Al}_{2} \mathrm{O}_{3}, \mathrm{SiO}_{2}, \mathrm{MgO}, \mathrm{HfO}_{2}, \mathrm{ZrO}_{2}$ and $\mathrm{Y}_{2} \mathrm{O}_{3}$ that are irreducible while the SMSI concerns $\mathrm{TiO}_{2}$, $\mathrm{Ta}_{2} \mathrm{O}_{5}, \mathrm{Nb}_{2} \mathrm{O}_{5}, \mathrm{CeO}_{2}$ that are reducible [6-8]. The choice of focusing on bulk structures rather than on surfaces thus obeys two reasons: first, to deal with a structural model simpler than the surfaces, getting rid of the excess reactivity of undercoordinated surface atoms and second, to provide the basis to compare bulk and surface reactivity. The text contains thus comments and remarks for surface reactivity when they are felt to be constructive for the comprehension of the reducibility mechanisms. 


\begin{tabular}{|c|c|c|c|c|c|c|c|c|c|c|c|c|c|c|c|c|c|}
\hline $\begin{array}{r}\text { Oxidation } \\
\text { state } \downarrow\end{array}$ & $\mathrm{Mg}$ & Sc & $Y$ & $\mathrm{Ti}$ & $\mathrm{Zr}$ & $\mathrm{Hf}$ & $\mathrm{Ce}$ & $\mathrm{v}$ & $\mathrm{Nb}$ & $\mathrm{Ta}$ & $\mathrm{Cr}$ & $\mathbf{w}$ & $Z n$ & Al & Ga & $\mathrm{Si}$ & Sn \\
\hline$\overline{V I}$ & & & & & & & & & & & $\mathrm{CrO}_{3}$ & $\mathrm{WO}_{3}$ & & & & & \\
\hline v & & & & & & & & $\mathrm{V}_{2} \mathrm{O}_{5}$ & $\mathrm{Nb}_{2} \mathrm{O}_{5}$ & $\mathrm{Ta}_{2} \mathrm{O}_{5}$ & $\mathrm{Cr}_{3} \mathrm{O}_{4}$ & & & & & & \\
\hline IV & & & & $\mathrm{TiO}_{2}$ & $\mathrm{ZrO}_{2}$ & $\mathrm{HfO}_{2}$ & $\mathrm{CeO}_{2}$ & $\mathrm{vO}_{2}$ & $\mathrm{NbO}_{2}$ & $\mathrm{TaO}_{2}$ & $\mathrm{CrO}_{2}$ & $\mathrm{WO}_{2}$ & & & & $\underline{\mathrm{SiO}_{2}}$ & $\mathrm{SnO}_{2}$ \\
\hline & & & & $\mathrm{Ti}_{3} \mathrm{O}_{5}$ & & & & $\mathrm{~V}_{3} \mathrm{O}_{5}$ & & & & & & & & & \\
\hline III & & $\underline{\mathrm{Sc}_{2} \mathrm{O}_{3}}$ & $\underline{\mathrm{Y}_{2} \underline{\mathrm{O}}_{3}}$ & $\mathrm{Ti}_{2} \mathrm{O}_{3}$ & $\left(\mathrm{Zrl}_{3}\right)$ & $\left(\mathrm{HfI}_{3}\right)$ & $\mathrm{Ce}_{2} \mathrm{O}_{3}$ & $\mathrm{~V}_{2} \mathrm{O}_{3}$ & & & $\mathrm{Cr}_{2} \mathrm{O}_{3}$ & & & $\underline{\mathrm{Al}_{2} \mathrm{O}_{3}}$ & $\mathrm{Ga}_{2} \mathrm{O}_{3}$ & & \\
\hline & & & & $\mathrm{Ti}_{3} \mathrm{O}_{5}$ & & & & $\mathrm{~V}_{3} \mathrm{O}_{5}$ & & & $\mathrm{Cr}_{3} \mathrm{O}_{4}$ & & & & & & \\
\hline II & $\underline{\mathrm{MgO}}$ & & & $\mathrm{TiO}$ & & & & & $\mathrm{NbO}$ & $\mathrm{TaO}$ & $\mathrm{Cr}_{3} \mathrm{O}_{4}$ & & $\begin{array}{l}\mathrm{ZnO} \\
\mathrm{ZnO}_{2}\end{array}$ & & $\mathrm{GaO}$ & & SnO \\
\hline I & & & & & & & & vo & & & & & & & $\mathrm{Ga}_{2} \mathrm{O}$ & & \\
\hline
\end{tabular}

Table 1: Metal oxides of different stoichiometry and oxidation states of the cation (left column). They are presented according the group in the periodic table of the metal. MO-HOS from group IR are underlined in solid line. 


\subsection{Empirical classifications of reducibility}

Table 1 displays our selection of metal oxides with different oxidation states for the cation when known. A first empirical criterion to determine if a metal oxide is reducible is the existence of compounds with different stoichiometry. Thus, metals with only one stable oxidation state can be classified as irreducible. This is the case for $\mathrm{MgO}, \mathrm{Al}_{2} \mathrm{O}_{3}, \mathrm{SiO}_{2}$ and $\mathrm{Y}_{2} \mathrm{O}_{3}$ and that we will call from now on group IR. The presence of several possible stoichiometries suggests the possibility of reduction, as for $\mathrm{TiO}_{2}, \mathrm{CeO}_{2}, \mathrm{~V}_{2} \mathrm{O}_{5}, \mathrm{SnO}_{2}, \mathrm{Ta}_{2} \mathrm{O}_{5}$, $\mathrm{Nb}_{2} \mathrm{O}_{5}, \mathrm{CrO}_{3}, \mathrm{WO}_{3}$ and $\mathrm{Ga}_{2} \mathrm{O}_{3}$, this class will be denoted as group R. In the case of $\mathrm{HfO}_{2}$ and $\mathrm{ZrO}_{2}$, other oxides are not known; however the oxidation state III exists in salts (see iodides for instance). This defines a third group (INT) as an intermediate between the two others.

A finer description may divide each group into subclasses according to the formal charge of the cation (oxidation number). Thus $\mathrm{CrO}_{3}$ is labeled $\mathrm{R} 6$ and $\mathrm{Al}_{2} \mathrm{O}_{3}$, IR3. One can remark that oxidation numbers of class IR range from II to IV, the two oxides classified as INT are INT4 and the oxidation numbers of class $\mathrm{R}$ range from III to VI. Note however that the simple analysis of the cation oxidation state is not decisive in the classification: cations in the IV oxidation state, leading to tetravalent $\mathrm{MO}_{2}$ oxides, can be IR $\left(\mathrm{SiO}_{2}\right), \mathrm{R}\left(\mathrm{TiO}_{2}\right.$, $\left.\mathrm{CeO}_{2}\right)$ and INT $\left(\mathrm{ZrO}_{2}, \mathrm{HfO}_{2}\right)$. When the oxidation state of the cation is high, reducibility is more likely. Data for standard electrode potential (half equations for the capture of electrons from $\mathrm{M}^{\mathrm{n}+}$ ions in the highest oxidation states to the next) are incomplete but confirm the classification. They are negative for the IR and INT groups $\left(\mathrm{E}^{0}(\mathrm{Al})^{3+} / \mathrm{Al}\right)=-1.66 \mathrm{~V}, \mathrm{E}^{0}\left(\mathrm{Zr}^{4+} / \mathrm{Zr}\right)=-1.45 \mathrm{~V}$ and $\left.\mathrm{E}^{0}\left(\mathrm{Zn}^{2+} / \mathrm{Zn}\right)=-0.76 \mathrm{~V}\right)$ and positive for the $\mathrm{R}$ group $\left(\mathrm{E}^{0}\left(\mathrm{Sn}^{4+} / \mathrm{Sn}^{2+}\right)=+0.15 \mathrm{eV}\right.$ and $\left.\mathrm{E}^{0}\left(\mathrm{Ce}^{4+} / \mathrm{Ce}^{3+}\right)=+1.44 \mathrm{eV}\right)$

Coordination might be thought as another possible criterion. In the group $\mathrm{R}$, the $\mathrm{O}$ coordination varies from 3 in titania to 4 in ceria while in the group IR it varies from 2 in silica to 6 in magnesia. The nature of the cation (metal vs. nonmetal) does not discriminate between the groups: the R group contains nonmetal $(\mathrm{Sn})$, transition metal $(\mathrm{Ti})$ and rare earth $(\mathrm{Ce})$; the IR group, nonmetal ( $\mathrm{Si}$ ) and alkaline-earth metal $(\mathrm{Mg})$.

Pauling electronegativity might also be thought as a measure; however, the value is similar for the cation of oxides belonging to different groups, $1.8 \mathrm{eV}^{1 / 2}$ for $\mathrm{Sn}$ (group R) and Si (group IR), $1.5 \mathrm{eV}^{1 / 2}$ for $\mathrm{V}$ 
(group R) and Al (group IR). A related property of the bond i.e. ionicity or covalency, is not determining for this classification: $\mathrm{CrO}_{3}$ and $\mathrm{TiO}_{2}$ (group R) and $\mathrm{SiO}_{2}$ (group IR) are equally considered as covalent [9]. $\underline{\text { Partial }}$

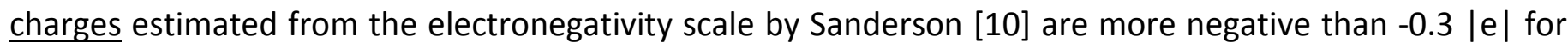
IR (and INT) oxides and less for R oxides; however it is very weak for for silica, $-0.23|e|$ that definitely belongs to the IR group.

The atomic configuration of the $\mathrm{M}^{(\mathrm{n}-1)+}$ ions after the capture of an electron from the cation in the highest oxidation states also seems to monitor the reducibility according to the nature of the level occupied by the electron of reduction; s states would be difficult to reach while $d$ and $f$ seem more accessible. The population of a $3 \mathrm{~s}$ shell, high in energy, correlates with irreducibility for $\mathrm{MgO} \mathrm{Al}_{2} \mathrm{O}_{3}$ and $\mathrm{SiO}_{2}$. However, that of a $4 \mathrm{~s}$ or a $5 \mathrm{~s}$ shell in the cases of $\mathrm{SnO}_{2}, \mathrm{Ga}_{2} \mathrm{O}_{3}$ and $\mathrm{ZnO}$ do not. On the other hand, all the oxides containing transition metals are not easily reducible. This is the case of $\mathrm{Y}_{2} \mathrm{O}_{3}$ classified as IR from table 1 whose dipositive cations have $\mathrm{d}^{1}$ electronic configuration $[11,12]$. This is also the case of INT oxides $\left(\mathrm{HfO}_{2}\right.$ and $\left.\mathrm{ZrO}_{2}\right)$.

Besides the problems in the definition of the non-observable descriptors discussed here, reducibility does not seem to be correlated with a single structural or electronic property.

\section{Describing reducibility from calculations}

\subsection{Electronic structure of common metal oxides: the band gap}

The electronic structure of our selection of metal oxides is characterized by an electronic gap separating the valence band, fully occupied, and a conduction band, empty. The former is made of the crystal orbitals of the oxygen dianion while the latter corresponds to the empty atomic levels of cations; this analysis that neglects the delocalization due to the conjugation of orbitals is the essence of formal oxidation numbers and leads to an ideal electron count. This description corresponds to semiconductors or insulators. Note that our selection is not exhaustive and does not include metal oxides in which the cation has an oxidation state larger than $\mathrm{VI}$ (such as $\mathrm{Re}_{2} \mathrm{O}_{7}, \mathrm{OsO}_{4}$ or $\mathrm{RuO}_{4}$ for instance). It also excludes those whose cations belong to the columns 8-11 of the periodic table $\left(\mathrm{Fe}_{2} \mathrm{O}_{3}, \mathrm{CoO}, \mathrm{Ni}_{2} \mathrm{O}_{3}, \mathrm{CuO}\right.$ or $\left.\mathrm{Au}_{2} \mathrm{O}_{3}\right)$ which 
represents cases where the top of the valence band consists of d-electron states, in contrast to the $O 2 p$ states. $\mathrm{ZnO}$ is special in the list since $\mathrm{Zn}$ possesses $3 \mathrm{~d}$ electrons, with electronic configuration for $\mathrm{Zn}^{2+} 3 \mathrm{~d}^{10}$ $4 s^{0}$. The electronic structure of the oxide presents $02 p$ states at the top of the conduction band, and $\mathrm{Zn} 4 \mathrm{~s}$ states at the bottom of the conduction band[13] It is thus characterized by an electronic gap and a conduction band on the metal cation that may be populated under reduction.

The energetic band gap appearing between the valence and conduction bands is therefore related to the reducibility of a metal oxide. It is easier to reduce a semiconductor than an insulator so that the trend for the gap width is an indication of reducibility. For insulators, the gap is large and reactivity is controlled by the preservation of the electron count [14-16]. The situation is different for semiconductors: valence and conduction bands get closer and this makes the systems more reactive.

The calculation of band gaps from density functional calculations suffers from a severe underestimation of the values due to an improper description of the conduction band. However, despite this systematic deviation, the comparison of calculated band gaps for different materials is still useful, and will be used as a descriptor for the study of reducibility trends. In section 4.1 we display the experimental values for the gap, measured by different means. Trends are indeed the same than those calculated here with a unique methodology and allow the classification of oxides into the same three classes.

\subsection{Formation of oxygen vacancies}

Reducibility is connected to the decrease of the metal oxidation state. This can be afforded experimentally by removing oxygen from the material resulting in a modified stoichiometry. The reduced oxide often, but not always, presents an enhanced reactivity compared to the stoichiometric oxide. The mechanism of creation of an oxygen vacancy can be represented by the following equation:

$$
M O_{x}=M O_{x-1}+\frac{1}{2} O_{2}
$$

The removal of a neutral lattice oxygen is energetically costly, and the higher the energy involved in the process, $E_{v a c}$, the less reducible the material. Equation (1) has the advantage of being easily measurable by computational techniques, from the total energy of the stoichiometric $\mathrm{MO}_{\mathrm{x}}$, reduced $\mathrm{MO}_{\mathrm{x}-1}$ and gas-phase 
$\mathrm{O}_{2}$ systems, providing a numerical value for the extension of reduction in a metal oxide. Note that the energy $E_{\mathrm{vac}}$ obtained will depend on the local structure of the oxygen site removed. As a rule of thumb, the lower the coordination, the smaller the value of $E_{\mathrm{vac}}$.

Several studies give already information on oxygen vacancies in transition metal and rare earth oxides surfaces. The main one is the review by Ganduglia-Pirovano et al. [17] that concerns $\mathrm{TiO}_{2}, \mathrm{ZrO}_{2}, \mathrm{~V}_{2} \mathrm{O}_{5}$ and $\mathrm{CeO}_{2}$. We have repeated these calculations for consistency of results comparing oxides but we only present more detailed presentation for less studied materials.

\subsection{Electron localization in reduced metal oxides}

\subsubsection{Adding an extra electron}

Since reduction involves the presence of excess electrons compared to the stoichiometric oxide, a rough way of mimicking reduced oxides can be made by adding an extra electron to the stoichiometric compound. This electron cannot be stabilized in the oxygen anionic levels of the valence band and has to find available energetic levels higher in energy, as happens in a reduced system. The resulting system is negatively charged, and the difference in energy between the anionic and neutral systems is related to the reducibility of the material; it corresponds formally to the definition of electron affinity. This is a rough approximation but has the advantage of giving an image of the reduction electron in the crystal structure, without geometrical distortion due to the removal of lattice oxygen, as described above. Table 2 presents the values obtained in the present work.

\begin{tabular}{|l|r|r|}
\hline Oxides & $E(e V)$ & supercell \\
\hline $\mathrm{Al}_{2} \mathrm{O}_{3}$ & 12.82 & $(2 \times 2 \times 1)$ \\
\hline $\mathrm{MgO}$ & 9.79 & $(2 \times 2 \times 2)$ \\
\hline $\mathrm{SnO}_{2}$ & 8.39 & $(2 \times 2 \times 3)$ \\
\hline $\mathrm{CeO}_{2}$ & 7.64 & $(2 \times 2 \times 2)$ \\
\hline $\mathrm{HfO}_{2}$ & 7.46 & $(2 \times 2 \times 2)$ \\
\hline $\mathrm{SiO}_{2}$ & 7.44 & $(2 \times 2 \times 2)$ \\
\hline $\mathrm{Sc}_{2} \mathrm{O}_{3}$ & 6.65 & $(1 \times 1 \times 1)$ \\
\hline $\mathrm{ZrO}_{2}$ & 6.58 & $(2 \times 2 \times 2)$ \\
\hline $\mathrm{Y}_{2} \mathrm{O}_{3}$ & 6.04 & $(1 \times 1 \times 1)$ \\
\hline $\mathrm{TiO}_{2}$-rutile & 5.36 & $(2 \times 2 \times 3)$ \\
\hline${\mathrm{B}-\mathrm{Ga}_{2} \mathrm{O}_{3}}^{\mathrm{TiO}_{2}-\text { anatase }}$ & 4.86 & $(1 \times 3 \times 2)$ \\
\hline
\end{tabular}




\begin{tabular}{|l|l|r|}
\hline $\mathrm{Ta}_{2} \mathrm{O}_{5}$ & 3.89 & $(2 \times 2 \times 2)$ \\
\hline $\mathrm{ZnO}$ & 3.14 & $(3 \times 3 \times 2)$ \\
\hline $\mathrm{Nb}_{2} \mathrm{O}_{5}$ & 2.40 & $(1 \times 2 \times 1)$ \\
\hline $\mathrm{WO}_{3}$ & 1.56 & $(2 \times 2 \times 1)$ \\
\hline $\mathrm{V}_{2} \mathrm{O}_{5}$ & 1.48 & $(1 \times 3 \times 2)$ \\
\hline $\mathrm{CrO}_{3}$ & 0.25 & $(2 \times 1 \times 2)$ \\
\hline
\end{tabular}

Table 2: Vertical Electronic affinities (VEA) of metal oxides (one electron is added per supercell).

\subsubsection{Localization of the extra electrons after formation of an oxygen vacancy}

The creation of an oxygen vacancy also leads to the presence of excess electrons, namely two electrons per vacancy. The process can be schematized as follows:

$$
O_{\text {lattice }}^{2-} \rightarrow 2 e^{-}+\frac{1}{2} O_{2(g)}
$$

The fate of the two electrons left is also connected to the reducibility of the metal cation. Thus, if the metal cation is not reducible, the electrons may stay in the lattice position occupied by the oxygen atom removed, resulting in an F-center (see scheme 1). The stabilization of these electrons is done by the Madelung field of the crystal lattice. Their electronic signature is a localized state in the middle of the band gap, detached from the valence band but close to it, of oxygen character, filled with two electrons. F-centers are very reactive basic and reducing sites.

$$
\text { Irreducible cation: } \mathrm{M}^{\mathrm{n}+}-\mathrm{O}^{2-}-\mathrm{M}^{\mathrm{n}+} \rightarrow \mathrm{M}^{\mathrm{n}+}-2 \mathrm{e}^{-}-\mathrm{M}^{\mathrm{n}+}+1 / 2 \mathrm{O}_{2}
$$

$$
\text { Reducible cation: } \mathrm{M}^{\mathrm{n}-}-\mathrm{O}^{2-}-\mathrm{M}^{\mathrm{n}+} \rightarrow \mathrm{M}^{(\mathrm{n}-1)+}-\square-\mathrm{M}^{(\mathrm{n}-1)+}+1 / 2 \mathrm{O}_{2}
$$

Scheme 1: removal of a lattice oxygen results in the formation of F-centers for irreducible cations, or to a decrease in the oxidation state of the metal for reducible cations.

On the contrary, when cations are reducible they possess electronic levels available for accepting the electrons left by the oxygen removed. These results in the decrease of their oxidation state (see scheme 1). Upon reduction the metal sites become (partially) filled. The electronic signature in the band structure is the shift of the Fermi energy to the conduction band, sometimes a localized state appears, detached from 
the conduction band, with cationic predominant character. The usual situation is the reduction of two cationic sites, each one with one electron, rather than one cationic site with two electrons. The former leads to unpaired electrons and in a triplet state $\left(T, N_{\alpha}-N_{\beta}=2\right)$ or in an antiferromagnetic singlet state (SA, $\left.N_{\alpha}=N_{\beta}=1\right)$. The overlap between the singly occupied valence orbitals on the cation may generate some spin electron density close to the vacant site; however, taking high isodensity contours, the density should split in separate domains and localize on the cations. This different behavior also should characterize the oxides as reducible, irreducible or intermediate and, as a consequence, can be used to predict their behavior in certain reactions.

Thus, unraveling the factors influencing oxides defect formation should clarify the mechanisms involved in the stabilization of reduced systems. This will help understanding and predicting the material's reactivity, and serve as a guide in the search of novel catalytic materials with tailored properties. A comparison within an oxide series could permit the emergence of factors influencing oxides' reducibility.

\section{$\underline{2.4}$ Implications for surfaces and adsorption processes}

Adsorption of molecules on stoichiometric oxides often involves the formation of dative bonds occurring with acid-base mechanisms and maintaining the ideal count with the electronic gap associated with stoichiometry [14-16,18]. However for irreducible oxides, since the gap separating the Frontier Orbitals is large, their surfaces are not very reactive and adsorption strength is generally weak, often insufficient to dissociate adsorbates. When adsorbates dissociate on a surface the bond cleavage is formally heterolytic, the fragments being adsorbed on surface ions of opposite charges. This concerns even homopolar molecules such as $\mathrm{H}_{2}$ and $\mathrm{Cl}_{2}$. For $\mathrm{H}_{2}$, one hydride $\left(\mathrm{M}-\mathrm{H}^{-}\right)$and one hydroxyl $\left(\mathrm{O}-\mathrm{H}^{+}\right)$ species are formed $[14,16]$. In fact, this rule is formal rather than a picture close to reality; it tells more about the site distribution for $\mathrm{H}$ or $\mathrm{Cl}$ in the hydrogenated (chlorinated) surfaces and does not discuss their formation, the dissociation of molecules being not so easy. Note that when surface oxygen is missing, the $\mathrm{O}$ vacancies must accommodate unstable electron pairs and be very reactive. Our comment 
concerns clean surface, e.g. ultra-high vacuum UHV and dry conditions. Surface hydroxylation may change this picture, covering all the sites and leaving only Brønsted sites with weaker interactions.

The situation is different for semiconductors: they are more reactive due to a smaller gap and their surfaces dissociate adsorbates more easily. However, the main difference is not only quantitative. A different adsorption mechanism may occur, involving a redox process instead of an acid-base one. The ideal electron count can be more easily violated since cations of the MO-HOS may be reduced. It follows that adsorption of radicals (many electron donor atoms such as $\mathrm{H}$ and metals are radicals) can more easily be done as protons (or cations) at a O surface site, the extra electron being simultaneously transferred to metal cations of the metal oxide. $\mathrm{H}_{2}$ adsorption leads to two surface hydroxyl groups. Metals are also adsorbed as $\mathrm{M}^{\mathrm{n}+}$ with a reduction of the oxide support; the oxide may even be further reduced when this is necessary for the reactivity of the metal adsorbed. The recombination of surface hydroxyl groups may lead to the formation of water, leaving an oxygen vacancy. The surface oxygen coordination is related to its reactivity and in general terms the lower the coordination the higher the reactivity [19-21].

When the oxide is reduced by intrinsic structural defect formation ( $O$ vacancy), by hydrogenation or by doping, the presence of "excess" electrons with respect to the perfect stoichiometric oxide modifies the interaction between the oxide and an adsorbate. These two first reductive modes are similar; in the presence of water, the vacancies of the $\mathrm{O}$ defective surface are saturated and the surface is a hydrogenated perfect surface. The excess electrons are very reactive when they are unstable in proportion to the cost energy of the formation of the reduced oxide.

\section{3) Computational details}

We present results using several DFT functionals: $\mathrm{PBE}, \mathrm{PBE}+\mathrm{U}$ and hybrid functional (B3LYP).

\subsection{The periodic approach within density functional theory}

In the present study we have adopted a periodic approach within density functional theory using pure PBE functional [22]. This functional permits a correct description of oxygen vacancy formation 
energies $E_{v a c}\left(1 / 2 O_{2}\right)$. The core electrons were treated with standard PAW_PBE pseudopotentials $[23,24]$, while the valence electrons were described with plane wave basis set $\left(E_{\text {cutoff }}=400 \mathrm{eV}\right)$, including the following electronic configurations : O [1 $\left.1 s^{1} 2 s^{2} 2 p^{4}\right], M g\left[3 s^{2}\right], Y\left[4 s^{2} 4 p^{6} 4 d^{1} 5 s^{2}\right], \operatorname{Ti}\left[3 p^{6} 3 d^{2} 4 s^{2}\right], Z r\left[4 d^{2} 5 s^{2}\right]$, $H f\left[5 d^{2} 6 s^{2}\right]$, Ce $\left[4 f^{1} 5 s^{2} 5 p^{6} 5 d^{1} 6 s^{2}\right], V\left[3 p^{6} 3 d^{3} 4 s^{2}\right], N b\left[4 d^{4} 5 s^{1}\right], T a\left[5 p^{6} 5 d^{3} 6 s^{2}\right], \operatorname{Cr}\left[3 p^{6} 3 d^{5} 4 s^{1}\right], W\left(5 d^{5} 6 s^{1}\right), Z n$ $\left[4 d^{10} 5 s^{2}\right]$, Al $\left[3 s^{2} 3 p^{1}\right]$, Ga $\left[4 s^{2} 4 p^{1}\right]$, Si $\left[3 s^{2} 3 p^{2}\right]$, Sn $\left[4 d^{10} 5 s^{2} 5 p^{2}\right]$. A set of k-points distanced by $0.05 \AA^{-1}$ in the reciprocal space was used in the optimization procedure, while for density of states (DOS) calculations a denser grid $\left(0.025 \AA^{-1}\right)$ was applied. Only atomic positions were optimized. Crystallographic parameters of unit cells were fixed to their experimental values. The relaxed structures, stoichiometric and reduced, can be found online [25]. All the simulations were carried out using VASP 4.6 modeling package [26-29]. Images of structures were made with VESTA graphical package [30]. We use the terms of singlet state and triplet states when the number of unpaired electrons is 0 and 2 per unit cell; this has the advantage of speaking the same language as for molecular chemistry even if it is not a rigorous notation for crystal materials.

\subsection{Choice of $U$ parameter in DFT+U approach}

Pure GGA functionals are known to underestimate band gaps, and, for reducible oxides, are unable to give a correct electronic structure [17]. Introducing a Hubbard correction in the metal virtual states allows improving the localization [1,31,32]. For this reason, in section 4.2 we report the electronic structure using this correction for reducible oxides. Applied Hubbard $U-J$ parameters $\left(U_{\text {eff }}\right.$ in the following) are listed in Table 3 . There is an arbitrary choice of the $U_{\text {eff }}$ parameters and the specific value of $U_{\text {eff }}$ remains a matter of debate, its choice strongly influencing the results obtained. In addition, there is no guarantee that a good value for a given observable will be appropriate for another one. A correct description of electronic structure does not guarantee the reliability of reduction energetics. Indeed, the choice of $U_{\text {eff }}$ parameter may influence the oxides' reducibility order and therefore, in order to compare the energies of oxygen vacancy formation we have used no Hubbard correction, treating them on equal footing. 
Note however, that reasonable Hubbard corrections have a limited effect on the $\mathrm{E}_{\mathrm{vac}}\left(1 / 2 \mathrm{O}_{2}\right)$. In most of the cases, the calculations give an increase of the $E_{v a c}\left(1 / 2 \mathrm{O}_{2}\right)$ which could be explained by a larger energy penalty associated with $U_{\text {eff; }}$ on the reduced system electrons are transferred to the cation. There are two exceptions, $\mathrm{V}_{2} \mathrm{O}_{5}$ and $\mathrm{CrO}_{3}$.

Three reducible oxides $-\mathrm{TiO}_{2}, \mathrm{~V}_{2} \mathrm{O}_{5}$, and $\mathrm{CeO}_{2}$ - have been previously extensively studied on $\mathrm{DFT}+\mathrm{U}$ level. Concerning $\mathrm{TiO}_{2}$, two sets have been proposed, that can be simplified to small values (U $\left.\leq 4 \mathrm{eV}\right)$ and large ones $\left(U_{\text {eff }}>4.2 \mathrm{eV}\right)$. The latter is justified by a fit of the band gap on the bulk $\left(U_{\text {eff }}=8 \mathrm{eV}\right.$ [33]) or on a slab $\left(U_{\text {eff }}=4.2 \mathrm{eV}[34]\right)$. Nevertheless it does not give a correct description of the electronic levels $[1,31]$ that is better obtained by a small value. We have chosen $3.8 \mathrm{eV}$ as in ref. [1]. Note that the increase of $\mathrm{E}_{\mathrm{vac}}\left(1 / 2 \mathrm{O}_{2}\right)$ is limited with this value (from $4.84 \mathrm{eV}$ to $5.48 \mathrm{eV}$ for the $2 \times 2 \times 2$ cell of rutile) while it is clearly excessive using a large $U_{\text {eff }}$ (from $4.84 \mathrm{eV}$ to $9.49 \mathrm{eV}$ for the same cell and $U_{\text {eff }}=4.2 \mathrm{eV}$ ). Similarly Scanlon et al. [35] have found a much more reasonable description of $\mathrm{V}_{2} \mathrm{O}_{5}$ when using a moderate on-site Coulomb interaction, $U_{\text {eff }}=4.0 \mathrm{eV}$, instead of a larger value $\left(U_{\text {eff }}=6.6 \mathrm{eV}\right.$ was previously proposed by Laubachet al. [36] by fitting the calculated valence-band-conduction-band gap to the experimental value).

Several Hubbard terms have been investigated for a good description of defective $\mathrm{CeO}_{2}$. Fabris et al. [37] have used a small one site Coulomb term, $U_{\text {eff }}=1.5 \mathrm{eV}$, for GGA_PBE_+U following Cococcioni et al. [38] who proposed $U_{\text {eff }}=1.5-2.0 \mathrm{eV}$ for the GGA_PBE_+ $U$. The adequacy was a matter of discussion $[39,40]$. Fabris et al. [41] have used $U_{\text {eff }}=4.5 \mathrm{eV}$ for $G G A \_P B E+U$ and obtained insulating antiferromagnetic ground state with $E_{v}\left(1 \frac{1}{2} \mathrm{O}_{2}\right)=5.55 \mathrm{eV}$ using an appropriate Ce- $4 \mathrm{f}$ atomic orbital projector. Nolan et al. [42] and Jiang et al. $[43,44]$ have shown that a larger value, $U_{\text {eff }}=5$ (PW91) or 6.3 eV (PBE), was necessary to be closer to experiment. According to Illas et al. [45] a well-balanced choice of $U_{\text {eff }}$ is proposed to be slightly larger at $2-3 \mathrm{eV}$ for the $\mathrm{GGA}+\mathrm{U}$ ones. At variance with the cases of other oxides, in the case of ceria larger $U_{\text {eff }}$ values are shown to be more appropriate than small ones 
[45]. In section 3.2.3.1, we present results for different $U_{\text {eff }}$ values; a large $U$ is necessary to have a complete localization.

For $\mathrm{Ta}_{2} \mathrm{O}_{5}$ we have taken $\mathrm{U}_{\text {eff }}=4 \mathrm{eV}$. A weaker value $\mathrm{U}=1.35$ taken from ref [46] is insufficient to detach the electronic state corresponding to the vacancy from the conduction band. A larger value is necessary to have a state in the gap.

\begin{tabular}{|c|c|}
\hline Oxide & $\mathrm{U}_{\text {eff }}(\mathrm{eV})$ \\
\hline $\mathrm{TiO}_{2}$ & $3.8[1]$ \\
\hline $\mathrm{CeO}_{2}$ & $2.5-4$ \\
\hline $\mathrm{V}_{2} \mathrm{O}_{5}$ & $4[35]$ \\
\hline $\mathrm{Nb}_{2} \mathrm{O}_{5}$ & 3.0 \\
\hline $\mathrm{Ta}_{2} \mathrm{O}_{5}$ & 4 \\
\hline $\mathrm{WO}_{3}$ & $2.5-4$ \\
\hline $\mathrm{CrO}_{3}$ & 2.5 \\
\hline $\mathrm{SnO}_{2}$ & 1 on $5 \mathrm{~s}$ orbital \\
\hline $\mathrm{ZnO}(3 \mathrm{~d})$ & $4.7[47], \mathrm{U}-\mathrm{J}=7-1[48], \mathrm{U}-\mathrm{J}=7.5[49]$ \\
\hline
\end{tabular}

Table 3. Selected Hubbard parameter for metal oxides of type IR.

\subsection{The hybrid approach using B3LYP}

The underestimation of the band gap by DFT, and the excessive delocalization of the electrons upon reduction, are due to the self-interaction error of pure DFT functionals. The inclusion of a part of exact exchange alleviates the problem and results in more realistic band gap values as well as a more localized picture of the electrons after reduction. Hybrid functionals that contain both exact nonlocal exchange (Hartree-Fock) and electronic correlation (DFT) have proven to describe better the electronic structure of reduced chemical systems. The calculation of exact exchange within periodic plane-wave codes needs more computational resources than with atomic basis sets, and results in heavy calculations compared to pure DFT where the exchange is neglected. On the other side, inclusion of pure exchange improves the description without using empirical correction parameters like the Hubbard $U_{\text {eff. }}$

We have chosen to use the B3LYP functional because it has been very popular for molecular systems in the past decades, and there are not much data in the literature of solid state systems obtained with this 
functional. Recent works in the literature have shown that the use of B3LYP functional correctly describes the band gap for a set of semiconductors and isolators [50], with only a small deviation compared to HSE $[51,52]$, the preferred functional in materials science $[53,54]$. It is worth noting that the two functionals show the same trends.

\subsection{Energetics of oxygen vacancy formation}

The energy of oxygen vacancy $\left(V_{0}\right)$ formation can serve as a reducibility criterion for a metal oxide. The higher the value of $E_{\mathrm{vac}}$, the less reducible the oxide. It can be reported with respect to oxygen atom or dioxygen molecule:

$$
\begin{aligned}
& E_{v a c}(O)=E(\text { surface with vacancy })+E(O)-E(\text { stoichiometric surface }) \\
& E_{v a c}\left(1 / 2 O_{2}\right)=E(\text { surface with vacancy })+1 / 2 E\left(O_{2}\right)-E(\text { stoichiometric surface })
\end{aligned}
$$

The PBE energies of atomic and molecular oxygen are $E(O)=-1.89 \mathrm{eV}$ and $E\left(\mathrm{O}_{2}\right)=-9.85 \mathrm{eV}$. The difference between these two values is related to the dissociation energy of oxygen molecule $\mathrm{O}_{2}$ in the following manner:

$$
E_{\text {diss }}\left(\mathrm{O}_{2}\right)=2 \cdot E(\mathrm{O})-E\left(\mathrm{O}_{2}\right)
$$

The experimental value of dissociation energy is of $(5.114 \pm 0.002)$ eV $[55,56]$. Our PBE value of $6.07 \mathrm{eV}$ is close to this one and other reported theoretical values obtained with a similar approach 5.81$6.14 \mathrm{eV}(\mathrm{PW} 91)$ [57]. $\mathrm{E}_{\mathrm{vac}}\left(1 \frac{1}{2} \mathrm{O}_{2}\right)=\mathrm{E}_{\mathrm{vac}}(\mathrm{O})+3.03$ may also be viewed as the Gibbs energy, $\mathrm{E}_{\mathrm{vac}}\left(1 \frac{1}{2} \mathrm{O}_{2}\right)+\mu(\mathrm{O})$, taking 0 as chemical potential for oxygen. Some authors propose a correction to the values of $E_{\mathrm{vac}}$ to account for the overbinding of the $\mathrm{O}_{2}$ molecule by pure DFT [58]. We have chosen to show the raw values without correction for $\mathrm{PBE}+\mathrm{U}$ and $\mathrm{B} 3 \mathrm{LYP}$.

The calculated $\mathrm{E}_{\mathrm{vac}}\left(1 / 2 \mathrm{O}_{2}\right)$ depend on the vacancy concentration, i.e. on the model size. To allow comparison within the obtained data, we will refer to the vacancy concentration as to the ratio $\mathrm{m} / \mathrm{n}$ between the number of vacancies $(m)$ and the total number of oxygen atoms $(n)$, per unit cell.

\section{$\underline{3.5 \text { Structural model }}$}


Most of the examined oxides exist in several crystalline phases, and only some of them were taken into account. In the present study we have explored oxygen vacancy in rutile and anatase phases of $\mathrm{TiO}_{2}$, monoclinic $\mathrm{ZrO}_{2}, \mathrm{HfO}_{2}, \mathrm{Ga}_{2} \mathrm{O}_{3}\left(\beta-\mathrm{Ga}_{2} \mathrm{O}_{3}\right)$, cubic $\mathrm{MgO}$ ( $\mathrm{NaCl}$-type) and $\mathrm{CeO}_{2}$ (fluorite type), trigonal (or hexagonal, depending on the axes choice) corundum $\mathrm{Al}_{2} \mathrm{O}_{3}$. Multiple unit cells were used in order to avoid the anisotropy and consider concentration effects (Table 2), built with the MAPS suite [59].

We tried to make the size of these models as similar as possible. The crystallographic parameters of the elementary unit cells were fixed to the experimental values (Table 4), the error with respect to optimized ones, present in the literature, does not exceed $0.1 \AA[60,61]$. The optimized supercells are available online [25].

$\mathrm{MgO}, \mathrm{CeO}_{2}, \mathrm{TiO}_{2}$ oxides contain only one type of oxygen atom: its coordination number is 6,4 and 3, respectively, in $\mathrm{MgO}, \mathrm{CeO}_{2}$ and $\mathrm{Al}_{2} \mathrm{O}_{3}, \mathrm{TiO}_{2}$. On the contrary, other $\mathrm{MO}-\mathrm{HOS}$ dispose of several types of oxygen sites; this increases the possibilities of vacancy formation. Monoclinic oxides $\mathrm{ZrO}_{2}, \mathrm{HfO}_{2}$, have two types of oxygen sites, 3-fold and 4-fold coordinated oxygen atoms. $\mathrm{CrO}_{3}$ has three kinds of $\mathrm{O}$ atoms, one bridging and two terminal atoms. $\mathrm{V}_{2} \mathrm{O}_{5}$ has four kinds of oxygen atoms, one terminal (or vanadyl oxygen), one bridging and two three-fold coordinated. $\beta-\mathrm{Ga}_{2} \mathrm{O}_{3}$ has two types of 3-fold oxygen atoms (denoted as $3 g$ and $3 v$ ) and one type of 4-fold oxygen atom.

\begin{tabular}{|c|c|c|c|c|c|c|c|}
\hline \multirow{2}{*}{ Oxide } & \multirow{2}{*}{$\begin{array}{c}\text { Crystalline } \\
\text { system }\end{array}$} & \multirow{2}{*}{$\begin{array}{l}\text { Spatial } \\
\text { group }\end{array}$} & \multicolumn{4}{|c|}{ Unit cell parameters } & \multirow[t]{2}{*}{ References } \\
\hline & & & $a, \AA$ & $b, \AA$ & $c, \AA$ & $\beta,{ }^{\circ}$ & \\
\hline $\mathrm{MgO}$ & Cubic & $\mathrm{Fm}-3 \mathrm{~m}$ & 4.21 & - & - & - & [62] \\
\hline $\mathrm{Y}_{2} \mathrm{O}_{3}$ & Cubic & la-3 & 10.604 & - & - & - & [63] \\
\hline $\mathrm{TiO}_{2}$ rutile & Tetragonal & $\mathrm{P}_{2} / \mathrm{mnm}$ & 4.594 & - & 2.959 & - & [64] \\
\hline $\mathrm{TiO}_{2}$ anatase & Tetragonal & 141/amd & 3.785 & - & 9.514 & - & [65] \\
\hline $\mathrm{ZrO}_{2}$ & Monoclinic & $\mathrm{P} 21 / \mathrm{c}$ & 5.150 & 5.212 & 5.315 & 99.23 & [66] \\
\hline $\mathrm{HfO}_{2}$ & Monoclinic & $\mathrm{P} 21 / \mathrm{c}$ & 5.118 & 5.169 & 5.297 & 99.18 & [67] \\
\hline $\mathrm{CeO}_{2}$ & Cubic & $\mathrm{Fm}-3 \mathrm{~m}$ & 5.41 & - & - & - & [68] \\
\hline
\end{tabular}




\begin{tabular}{|c|c|c|c|c|c|c|c|}
\hline $\mathrm{V}_{2} \mathrm{O}_{5}$ & Orthorhombic & Pmmn & 11.519 & 3.564 & 4.373 & - & [69] \\
\hline $\mathrm{Nb}_{2} \mathrm{O}_{5}$ & Monoclinic (I) & $\mathrm{P} 2 / \mathrm{m}$ & 21.153 & 3.8233 & 19.356 & 119.8 & [70] \\
\hline $\mathrm{Ta}_{2} \mathrm{O}_{5}$ & Hexagonal & $\mathrm{P} 6 / \mathrm{mmm}^{*}$ & 7.248 & & 3.88 & - & [71] \\
\hline $\mathrm{CrO}_{3}$ & Orthorhombic & Ama2 & 5.743 & 8.557 & 4.789 & - & [72] \\
\hline $\mathrm{ZnO}$ & $\begin{array}{l}\text { Hexagonal } \\
\text { Wurtzite }\end{array}$ & P63mc & 3.25 & & 5.207 & & [73] \\
\hline $\mathrm{WO}_{3}$ & Monoclinic & $\mathrm{P} 2{ }_{1} / \mathrm{m}$ & 7.732 & 7.758 & 7.731 & 90.0 & {$[74,75]$} \\
\hline $\mathrm{Al}_{2} \mathrm{O}_{3}$ & Hexagonal & $\mathrm{R}-3 \mathrm{c}$ & 4.758 & - & 12.982 & - & [76] \\
\hline $\mathrm{Ga}_{2} \mathrm{O}_{3}$ & Monoclinic & $\mathrm{C} 2 / \mathrm{m}$ & 12.23 & 3.04 & 5.80 & 103.7 & {$[77,78]$} \\
\hline $\mathrm{SiO}_{2}$ & Trigonal & $P 3121$ & 4.913 & - & 5.405 & - & [79] \\
\hline $\mathrm{SnO}_{2}$ rutile & Tetragonal & $\mathrm{P}_{2} / \mathrm{mnm}$ & 4.737 & - & 3.186 & - & {$[80,81]$} \\
\hline $\mathrm{ZnO}$ & Wurtzite & $\mathrm{P}_{3} \mathrm{mc}$ & 3.250 & 3.250 & 5.207 & 120 & [82] \\
\hline
\end{tabular}

Table 4. Parameters of primitive unit cells $(1 \times 1 \times 1)$ used to construct the supercells as defined in Table $2 . *$ $\mathrm{P} 6 / \mathrm{mmm}$ for the unreconstructed structure

\section{4) Results and discussion}

\subsection{Trends from band gaps}

As introduced above, the width of the band gap in a metal oxide band structure is a first indication of its reducibility. Indeed, reduction implies the filling of empty orbitals that should be the most accessible, whose energy is at the bottom level of the conduction band. These levels may be shifted in the band gap. It is well known that pure DFT functionals are not an excellent tool for the analysis of the electronic structures because of the incorrect treatment of self-correlation [17]; gaps are underestimated and $+U$ corrections may be necessary to improve the description. However, introducing Hubbard corrections will make the results dependent on a set of parameters while some trends can still be observed even with pure PBE functional used in our approach. Results without and with Hubbard correction are displayed in Table S1 together with other theoretical results and experimental ones. 
Trends are indeed similar and the Hubbard correction for reducible oxides does not affect the ordering. They show an evolution from insulating materials of group IR, to semiconductors for oxides of group R. Considering the PBE values in Table S1, two groups are clearly distinguished by a threshold of $3 \mathrm{eV}$. IR and INT oxides are above this limit. ZnO is a special case: it does not belong to the strict definition of MO-HOS, because $\mathrm{Zn}^{2+}$ has $3 \mathrm{~d}$ core electrons contrary to transition metal cations of the same line. The group INT is close to the limit. The R oxides are below this limit. Silica is number 2 in the list well above the INT oxide.

Further analysis shows that the order within each group shows variations compared to other classifications. There are also differences relative to experiments that can arise from the DFT methodology but also from the different techniques of measurement. In our calculations, $\mathrm{Ga}_{2} \mathrm{O}_{3}$ appears closer to $\mathrm{TiO}_{2}$ than the experimental value indicated from ref. [83]. Trends for cationic charges (oxidation numbers) seem to indicate an influence of the $\mathrm{O}$ coordination, a weaker gap for R6 and a larger one for R3. Silica (IR4) has a much larger gap than ZnO (IR2); coordination and ionicity must then be taken into account (see discussion below). However, the gap values for several IR3 oxides scramble the sequence. 


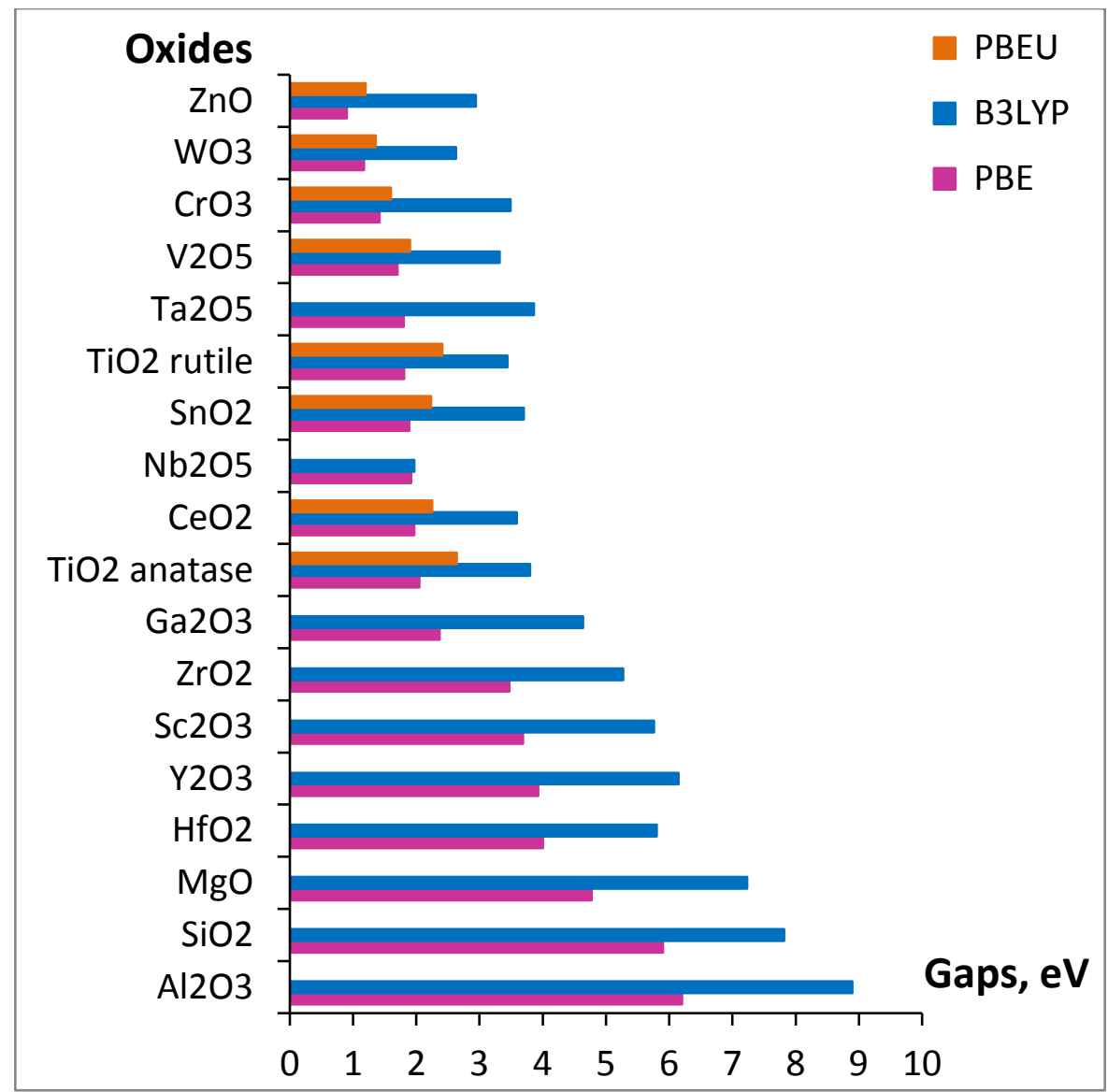

Figure 1 . Scaling the reducibility of the oxides using the gap criterion. We used 3 different approaches; DFT, DFT+U and B3LYP. The reducibility decreases from up to down.

\subsection{Trends from oxygen vacancy formation energies.}

The energies of formation of the vacancies (see Table S2 in the supplementary material) give a clear separation between the oxides. Figure 2 displays the formation energies of oxygen vacancies (from the least reducible to the most reducible oxide). Two groups appear separated by a limit of $\mathrm{E}_{\mathrm{vac}}=4 \mathrm{eV}$ (or $E_{\mathrm{vac}}(\mathrm{O})=8 \mathrm{eV}$ ). The cost for removing an $\mathrm{O}$ atom is larger for IR and INT oxides, smaller for $\mathrm{R}$ oxides. Silica has a smaller cost than expected. It is easier to remove an $\mathrm{O}$ atom than for INT oxides. The reason is the energy gain following the formation of a Si-Si bond. $\mathrm{ZnO}$ is the main exception that again classifies it as reducible. The trend is in agreement with recent results [84]. 


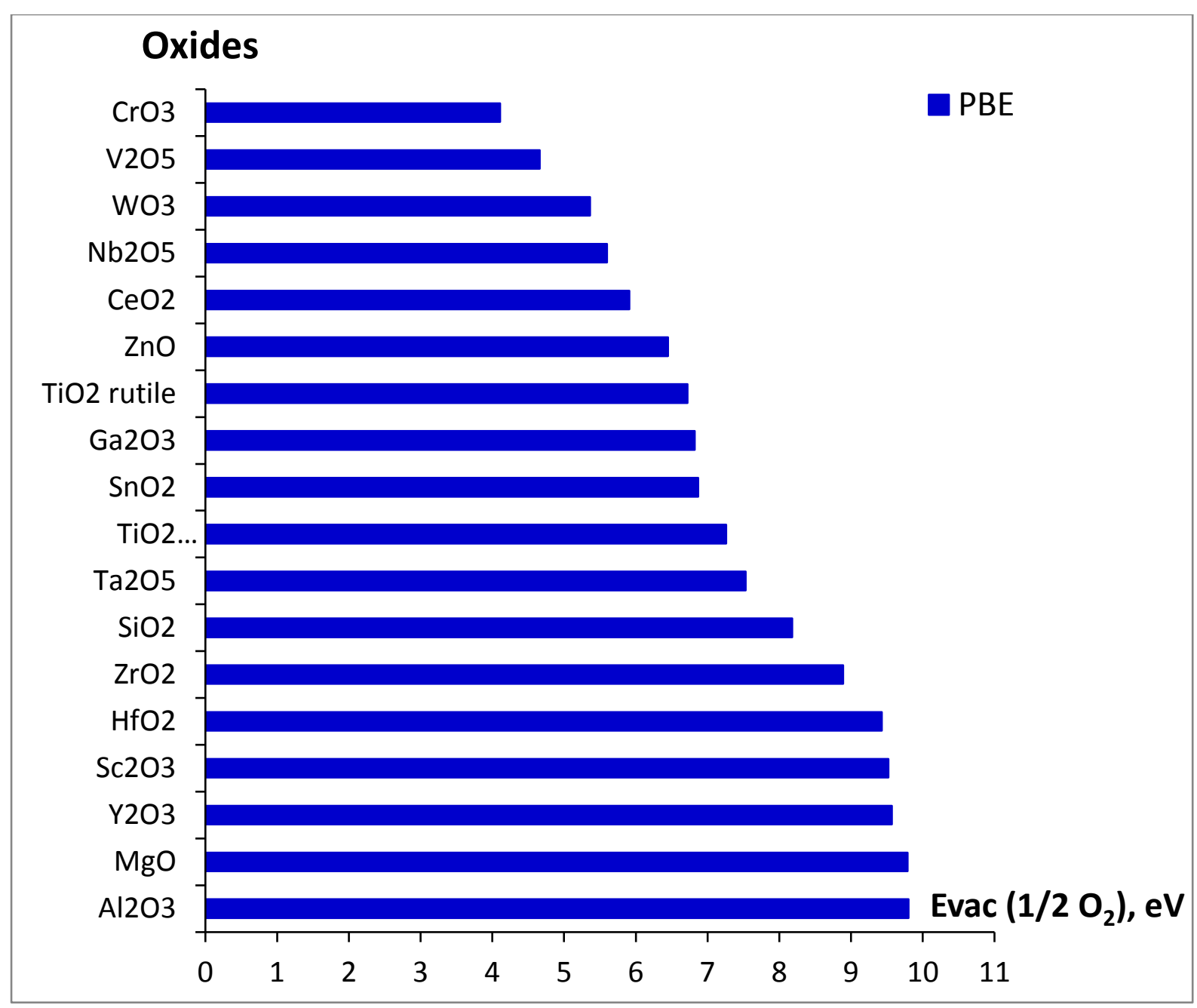

Figure 2. Scaling the reducibility of the oxides using the formation energy of the vacancy criterion. We display only the PBE values. The reducibility decreases from up to down.

\subsection{Trends from the electron localization}

The analysis of the electronic structure of reduced metal oxides can bring extremely valuable information on the stabilization of the excess electron(s) coming from the reduction process. Two main observations, the density of states DOS diagrams and the visualization of isosurfaces for charge or spin density, bring a detailed picture on the way a system stabilizes once reduced.

The density of states DOS diagrams allows seeing whether or not the reduced electrons are in a state in the gap. In the case of reducible oxides, we expect the localization of the electrons on the cations. The excess electrons occupy thus available cationic states that form the conduction band. The resulting electronic structure may be metallic (ferrimagnetic) if the spin orbitals mix with other 
conduction band states and the Fermi level is then in the conduction band. The reduced crystal may be viewed as an n-type semiconductor. Paying attention to the values of successive ionization potentials, it is always more favorable to reduce two sites than localizing two electrons on the same site; so it seems more favorable to generate a high-spin system (a triplet state based on the supercell in the terminology of quantum chemistry).

The second one is the presence and the position of a localized state in the gap for the DOS curve. The presence of such a state in the gap allows stabilizing the two excess electrons, maintaining $N_{\alpha}-N_{\beta}$ even integer. This is the case of F-center in $\mathrm{MgO}$, where the electrons are localized in the cavity formed after the removal of lattice oxygen. Then the excess electron density is found to be localized at the vacancy site. This picture "typically happens in insulating oxides" [85].

Visualizing the spin density difference $N_{\alpha}-N_{\beta}$, will lead to a delocalized picture where several cationic sites are involved. There is also the possibility of localizing the electrons in one or two different cationic sites close to the vacancy. This leads to diamagnetic (closed-shell singlet, when the electrons are paired on a single site), antiferromagnetic states (open-shell singlet, when the electrons are located on two cationic sites and have different spin), or ferromagnetic (triplet, when the electrons have the same spin). Visualizing the spin density difference will lead to a localized picture where two cationic sites are involved.

Note that the description above is idealized; the real systems calculated present deviations from these behaviors, either because of more complex electronic structure, or because of an artifact of the model or the method. Table 5, deduced from Table S2 in the supplementary materials (see "spin state") summarizes the most representative results obtained for the systems analyzed. In the following we will describe each of the systems calculated discussing the relevance of the band structure in the analysis of the reducible properties.

\subsection{Characterization of the reduced metal oxides}


In the present section we describe some representative compounds as regards the reducibility indices discussed above. The full set of systems described in detail can be found online [25].

MgO (IR2) is the most representative irreducible oxide. Due to the simplicity of its structure, one can find in the literature many studies on oxygen vacancy formation both in the bulk and on surface of $\mathrm{MgO}$, see for instance $[86,87]$. The $\mathrm{Mg}^{2+}$ and $\mathrm{O}^{2-}$ ions are octahedral and the bonding is highly ionic. The measured band gap in magnesium oxide is $7.8 \mathrm{eV}$ [87]. Our PBE value of $4.77 \mathrm{eV}$, although underestimates the experimental one as expected from DFT-GGA, clearly reproduces the energetic gap of an insulating system.

The formation energy of a bulk oxygen vacancy $\left(V_{6}\right), E_{v a c}(O)$, is close to $10 \mathrm{eV}$ (Table S2) and is an indication of the irreducibility of the material. Upon formation of the oxygen vacancy, the DOS exhibits a state in the gap as corresponds to an F-center, located above the valence band by $2.57 \mathrm{eV}$ (PBE) , 3.06 eV (B3LYP). This is in good agreement with experimental and comparable theoretical results $[88,89,87]$. The reduction electrons of the defective $\mathrm{MgO}$-structure are stabilized by the Madelung potential at the center of the O-vacancy and not localized on the neighboring metal cations, as can be seen in Figure 3.
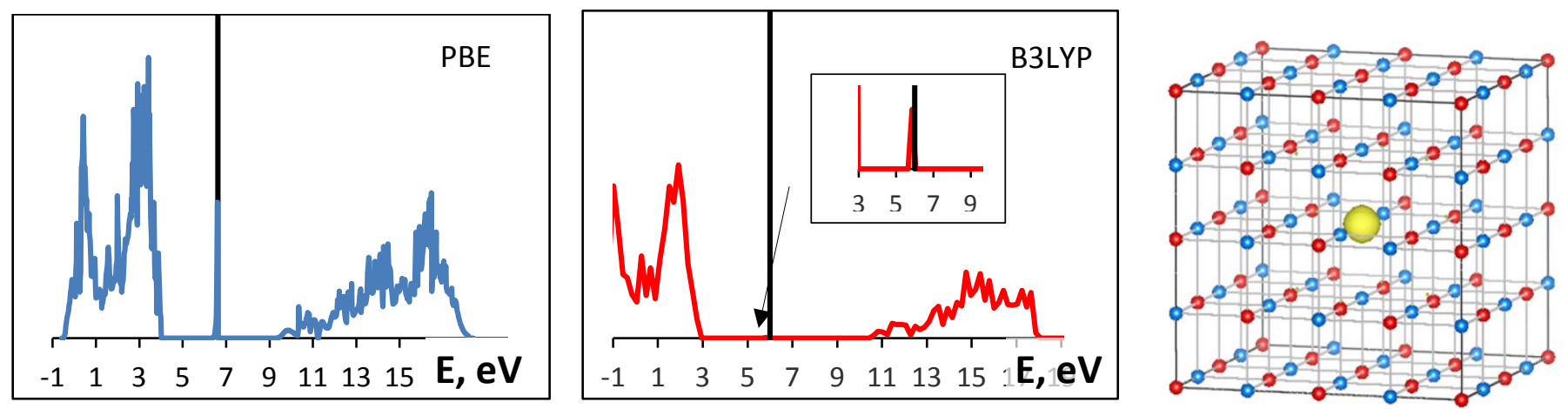

Figure 3: DOS in arbitrary units (left, middle), the vertical line indicates the Fermi level. A state in the gap appears. Right, view of the F-center in MgO (plot of the isosurface charge density), where the electron density is localized in the cavity.

$\mathrm{Al}_{2} \mathrm{O}_{3}$ (IR3) presents a similar description, with the high $\mathrm{E}_{\mathrm{vac}}$ values found in the series explained by the strong Madelung potential stabilizing the electrons in the vacancy. Quartz $\mathbf{S i O}_{\mathbf{2}}$ (IR4) presents however low $E_{\text {vac }}$ values because the oxygen in the lattice is only two-fold. In addition, after removal of 
this oxygen the Si-Si distance shortens, and the reduced system can be analyzed as presenting a covalent Si-Si bond. $\mathrm{Sc}_{2} \mathrm{O}_{3}$ and $\mathrm{Y}_{\mathbf{2}} \mathrm{O}_{\mathbf{3}}$ (IR3) show lower values of the band gap, 4.7-6.6 eV, but high $\mathrm{E}_{\mathrm{vac}}$ values. The electronic state after formation of an oxygen vacancy is singlet antiferromagnetic, contrary to the singlet diamagnetic found for the other irreducible compounds. The electron density of the reduced systems clearly shows an F-center with some extension on the neighboring Sc or $\mathrm{Y}$ atoms, and a state in the gap in the PBE+U calculation. The B3LYP calculation also presents a state in the gap for $\mathrm{Y}_{2} \mathrm{O}_{3}$ , but did not lead to an isolated state $\mathrm{Sc}_{2} \mathrm{O}_{3}$ which was unexpected.

ZnO (IR2) is a particular case. The absence of other oxidation states of $\mathrm{Zn}$ than +2 would classify $\mathrm{ZnO}$ as irreducible. However, it is often classified as a wide-band gap semiconductor of the II-VI group (n-type), with a band gap of $3.43 \mathrm{eV}[47,90]$. Our own comparison of gaps (Table S1) and formation energies of oxygen vacancies (Table S2) would classify $\mathrm{ZnO}$ as a reducible oxide. Compared to $\mathrm{MgO}, \mathrm{ZnO}$ appears to be clearly more reducible. The electronic structure of $Z n^{2+}$ is $3 d^{10} 4 s^{0}$. The presence of the $3 d$ shell completely filled accounts for the stability of the $\mathrm{Zn}^{2+}$ ion, while the 4 s shell, energetically close, may provide electronic states to accept extra electrons coming from reduction. This means that the reduction of $\mathrm{Zn}^{2+}$ might lead to metallic $\mathrm{Zn}$. 3d electrons may be considered as core electrons. UV photoemission measurements for bulk showed the $\mathrm{Zn} 3 \mathrm{~d}$ core level at about $7.5 \mathrm{eV}$ below the valence band and Surface states have been revealed in ARPES studies assigned to the $02 p$-derived dangling bond states $[13,91]$.

The band gap and $\mathrm{E}_{\mathrm{vac}}$ values are rather small compared to the previous irreducible oxides, but it forms F-centers upon creation of an O-vacancy (observed experimentally, see for instance [92-96]), with the corresponding localization of an electron pair in the lattice, together with some delocalization on neighboring $\mathrm{Zn}$ sites. The state in the gap only appears when using B3LYP, PBE gives a delocalized picture.

$\mathrm{CrO}_{3}(\mathbf{R} 6)$ chromia is a reducible material with a small band gap of $2.14 \mathrm{eV}$ and a variety of intermediate oxidation states. The calculated energies for creating oxygen vacancies are very small, 
0.16-3.27 eV $(\mathrm{U}=4 \mathrm{eV})$ or 1.07-3.56 eV $(\mathrm{U}=0 \mathrm{eV})$ for three types of oxygen (bridging, terminal horizontal and terminal vertical with respect to the chains). Terminal oxygen sites are easier to remove, due to an umbrella reconstruction that restores the fourfold coordination for the $\mathrm{Cr}$ atom that loses one ligand, also observed in $\mathrm{V}_{2} \mathrm{O}_{5}$.

Oxygen vacancy formation in $\mathrm{CrO}_{3}$ leads to the appearance of defect states in the band gap, despite its small width. Reduction electrons localize on $\mathrm{Cr}$ atoms adjacent to the oxygen vacancy, which is a feature of high reducibility (Figure 4).
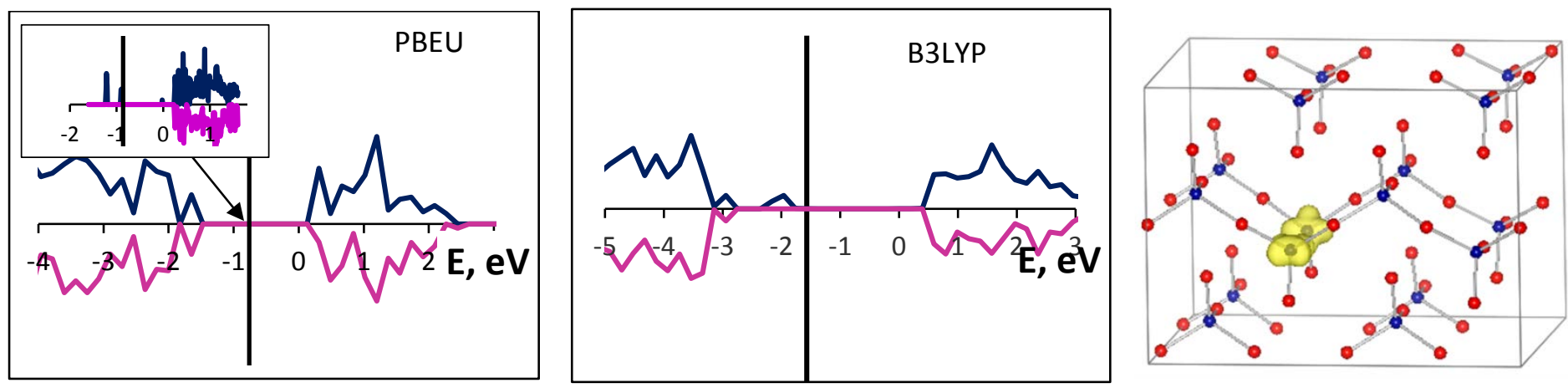

Figure 4: DOS in arbitrary units (positive values alpha spin, negative beta spin) in PBEU (left, U=2.5 eV) and B3LYP (middle) for vertical O-defective $\mathrm{CrO}_{3}$. The vertical line indicates the Fermi level. Right, isocontours of spin density are located on chromium sites.

The analysis of $\mathrm{CrO}_{3}$ is that of a prototypical reducible oxide. The efficient relaxation upon oxygen removal explains the small values of oxygen vacancy formation energies.

$\mathbf{W O}_{3}$ (R6) also presents small band gap (2.5-2.6 eV) and $\mathrm{E}_{\mathrm{vac}}$. The electronic state of lowest energy for the oxygen-defective system is a singlet. Whereas $\mathrm{PBE}+\mathrm{U}$ give a delocalized picture of the reduction electrons after oxygen removal (for $\mathrm{U}$ up to $4 \mathrm{eV}$ ), hybrid DFT calculations give a state in the gap [85]. The reduction leads to a $d^{1}$ state which remains above the levels of donor $(02 p)$ which leads to a semiconductor (except for the low temperature monoclinic phase, P2 $1 / c$ ). Di Valentin and Pacchioni [85] have drawn similar electron density plot using B3LYP method and conclude that most of the excess electrons are localized at the center of the vacancy. The presence of an F center for the most reducible 
oxide of the series explains the spin-paired configuration but clearly does not support a relation between F-center and irreducibility.

$\mathrm{TiO}_{2}$ (R4), extensively studied in the literature, presents low band gap and $\mathrm{E}_{\mathrm{vac}}$ for both rutile and anatase. Both polymorphs exhibit an antiferromagnetic singlet state upon formation of an oxygen vacancy, a state in the gap, as well as a localized picture of the electron density after reduction, centered on $\mathrm{Ti}$ sites neighboring the vacancy when using $\mathrm{PBE}+\mathrm{U}$ and B3LYP. A delocalized picture is found with pure DFT. A similar behavior is observed for $\mathbf{C e O}_{\mathbf{2}}(\mathbf{R 4}) . \mathbf{V}_{\mathbf{2}} \mathbf{O}_{\mathbf{5}}$ (R5) is characterized as reducible for all the descriptors used. The reducibility associated to the oxygen vacancy formation is connected to the presence of terminal oxygen sites and a layered structure. The removal of these sites is stabilized by a strong relaxation and bonding redistribution that results in a small energetic cost for creating the vacancy. Niobia $\mathbf{N b}_{2} \mathrm{O}_{5}$ (R5) presents smaller reducibility than $\mathrm{V}_{2} \mathrm{O}_{5}$, with a higher value of $E_{\mathrm{vac}}$ due to the lack of relaxation in the structure. A singlet diamagnetic state is found upon removal of an oxygen site and a state in the gap close to the conduction band with $\mathrm{Nb}$ sites occupied. Tantala $\mathrm{Ta}_{2} \mathrm{O}_{5}$ (R5) electronic structure after formation of an O-vacancy is that of an F-centre, but with a lower band gap, indicating potential reducible properties. Reducibility would come from the structural flexibility that allows an efficient accommodation of the electrons left upon oxygen removal in the crystal lattice, as in vanadia.

Rutile $\mathrm{SnO}_{2}$ (R4) show similar behavior although the electronic state found after formation of an oxygen vacancy is a singlet diamagnetic associated with the stability of the dication, $\mathrm{Sn}^{2+}$ with an atomic configuration $5 s^{2}$. This picture would imply electron localization as a sphere on tin atom neighboring the cavity or, by resonance, to a set of three spherical lobes on the three neighbors, but we obtain unexpectedly the picture of an F-center.

$\mathrm{ZrO}_{2}$ (INT4) and $\mathrm{HfO}_{2}$ (INT4) exhibit intermediate reducible behavior depending on the coordination of the defective sites. The high band gaps and $E_{v a c}$ values characterize them as irreducible. The formation of four-fold coordinated oxygen vacancies form F-centers (antiferromagnetic singlet), 
whereas less coordinated sites would promote the electron transfer to neighboring cations reducing them from +IV to +III states (triplet state). The two pictures are close in energy and the two behaviors may be observed.

$\mathrm{Ga}_{2} \mathrm{O}_{3}(\mathrm{R} 3)$ is expected to be irreducible since $\mathrm{Ga}$ belongs to the same family of $\mathrm{Al}$, and $\mathrm{Al}_{2} \mathrm{O}_{3}$ is typically irreducible. The experimental band gap is moderate, 4.4-4.9 eV, see Table $\mathrm{S} 1$, and $\mathrm{E}_{\mathrm{vac}}\left(1 \frac{1}{2} \mathrm{O}_{2}\right)$ values range between 3.79 and $4.42 \mathrm{eV}$ (Table S2) according to the vacancy site. The removal of oxygen sites leads to different pictures depending on their coordination as for $\mathrm{ZrO}_{2}$ or $\mathrm{HfO}_{2}$. In addition, relaxation stabilizes the formation of three-fold oxygen vacancies by formation of Ga-Ga bonds (similar to $\mathrm{SiO}_{2}$ ) with $\mathrm{E}_{\mathrm{vac}}$ values close to reducible systems like $\mathrm{TiO}_{2}$. In summary, gallia presents features of irreducible materials such as the formation of F-centers, but also some characteristic behavior of reducible materials (moderate band gap). Note that $\mathrm{Ga}^{+}$species $[97,98]$ have been characterized experimentally suggesting that electron transfer to $\mathrm{Ga}^{3+}$ is possible. 


\section{Comparison of electronic structures}

Table 5 summarizes the main results obtained in this work, gathering together all the indices and descriptors.

\begin{tabular}{|c|c|c|c|c|c|c|c|c|c|c|c|c|c|c|c|c|c|c|}
\hline $\mathrm{E}_{\mathrm{vac}}(\mathrm{O})$ & $\mathrm{WO}_{3}$ & $\mathrm{Nb}_{2} \mathrm{O}_{5}$ & $\mathrm{CrO}_{3}$ & $\mathrm{~V}_{2} \mathrm{O}_{5}$ & $\mathrm{CeO}_{2}$ & $\mathrm{ZnO}$ & $\mathrm{SnO}_{2}$ & $\mathrm{Ga}_{2} \mathrm{O}_{3}$ & $\mathrm{Ta}_{2} \mathrm{O}_{5}$ & $\mathrm{r}-\mathrm{TiO}_{2}$ & $\mathrm{a}-\mathrm{TiO}_{2}$ & $\mathrm{SiO}_{2}$ & $\mathrm{ZrO}_{2}$ & $\mathrm{HfO}_{2}$ & $\mathrm{SC}_{2} \mathrm{O}_{3}$ & $\mathrm{Y}_{2} \mathrm{O}_{3}$ & $\mathrm{MgO}$ & $\mathrm{Al}_{2} \mathrm{O}_{3}$ \\
\hline type & R6 & R5 & R6 & R5 & R4 & IR2 & R4 & R3 & R5 & R4 & R4 & IR4 & INT4 & INT4 & IR3 & IR3 & IR2 & IR3 \\
\hline $\begin{array}{c}\text { electronic } \\
\text { state }\end{array}$ & SD & SD & $T$ & $\mathrm{SA}, \mathrm{T}$ & $T$ & SD & SD & SD & $T$ & SA & SA & SD & SD & SD & SD & SD & SD & SD \\
\hline $\begin{array}{c}\text { Localizat } \\
\text { ion }\end{array}$ & Fcenter & $\begin{array}{l}\mathrm{Nb}-\mathrm{Nb} \\
\text { Bond }\end{array}$ & $\mathrm{Cr}^{5+}$ & $\mathrm{V}^{4+}$ & $\mathrm{Ce}^{3+}$ & Fcenter & Fcenter & $\begin{array}{l}\text { Ga-Ga } \\
\text { bond }\end{array}$ & $\begin{array}{l}\mathrm{Ta}^{4+} \\
\text { Fcenter }\end{array}$ & $\mathrm{Ti}^{3+}$ & $\mathrm{Ti}^{3+}$ & $\begin{array}{l}\text { Si-Si } \\
\text { bond }\end{array}$ & $\begin{array}{l}\mathrm{Zr}^{3+} \\
\text { Fcenter }\end{array}$ & Fcenter & Both & Both & Fcenter & Fcenter \\
\hline $\begin{array}{l}\text { VEA } \\
\text { ranking }\end{array}$ & $\mathrm{CrO}_{3}$ & $\mathrm{~V}_{2} \mathrm{O}_{5}$ & $\mathrm{WO}_{3}$ & $\mathrm{Nb}_{2} \mathrm{O}_{5}$ & $\mathrm{ZnO}$ & $\mathrm{Ta}_{2} \mathrm{O}_{5}$ & $\mathrm{a}-\mathrm{TiO}_{2}$ & $\mathrm{Ga}_{2} \mathrm{O}_{3}$ & $\mathrm{r}-\mathrm{TiO}_{2}$ & $\mathrm{Y}_{2} \mathrm{O}_{3}$ & $\mathrm{SC}_{2} \mathrm{O}_{3}$ & $\mathrm{ZrO}_{2}$ & $\mathrm{HfO}_{2}$ & $\mathrm{HfO}_{2}$ & $\mathrm{CeO}_{2}$ & $\mathrm{SnO}_{2}$ & $\mathrm{MgO}$ & $\mathrm{Al}_{2} \mathrm{O}_{3}$ \\
\hline $\begin{array}{l}\text { Band gap } \\
\text { ranking }\end{array}$ & $\mathrm{ZnO}$ & $\mathrm{WO}_{3}$ & $\mathrm{CrO}_{3}$ & $\mathrm{~V}_{2} \mathrm{O}_{5}$ & $\mathrm{Ta}_{2} \mathrm{O}_{5}$ & $\mathrm{TiO}_{2}$ & $\mathrm{SnO}_{2}$ & $\mathrm{Nb}_{2} \mathrm{O}_{5}$ & $\mathrm{CeO}_{2}$ & $\mathrm{TiO}_{2}$ & $\mathrm{Ga}_{2} \mathrm{O}_{3}$ & $\mathrm{ZrO}_{2}$ & $\mathrm{HfO}_{2}$ & $\mathrm{Sc}_{2} \mathrm{O}_{3}$ & $\mathrm{Y}_{2} \mathrm{O}_{3}$ & $\mathrm{MgO}$ & $\mathrm{SiO}_{2}$ & $\mathrm{Al}_{2} \mathrm{O}_{3}$ \\
\hline
\end{tabular}

Table 5: Summary of the results; IR oxides are in red, INT in green and R in blue. Details for the state correspond to the oxides as displayed on the first line. SD for singlet diamagnetic, $\mathrm{T}$ for triplet, SA for antiferromagnetic singlet. The separation for the $\mathrm{E}_{\mathrm{vac}}$ threshold ( $\left.8 \mathrm{eV}\right)$ is marked by the thick vertical line. The ranking by vertical energy affinity (VEA) and band gap is marked by the horizontal thick line. 
The energies of formation of the vacancies (Table S2) give a clear separation between the oxides of type $R\left(E_{\mathrm{vac}}(\mathrm{O})<8 \mathrm{eV}\right)$ and those of type $I R\left(E_{\mathrm{vac}}(\mathrm{O})>8 \mathrm{eV}\right)$. Plotting calculated $E_{\mathrm{vac}}$ energies vs. the experimental band gap shows the three types of behaviour i.e. reducible $R$, irreducible $I R$ and intermediate INT as can be observed in Figure 5. Silica appears with a small $E_{\text {vac }}$ value compared to the other systems of the R group. The compounds from group INT show $E_{\mathrm{vac}}$ values close to the IR ones but relaxation is less favorable and the electrons are trapped The classification obtained from the values of the electronic gap (Table S1) is the same. Again the separation between type R and type IR is clear, marked by a threshold of $3 \mathrm{eV}$. However, differences appear within each group. Silica is on the top of the values of the group IR.

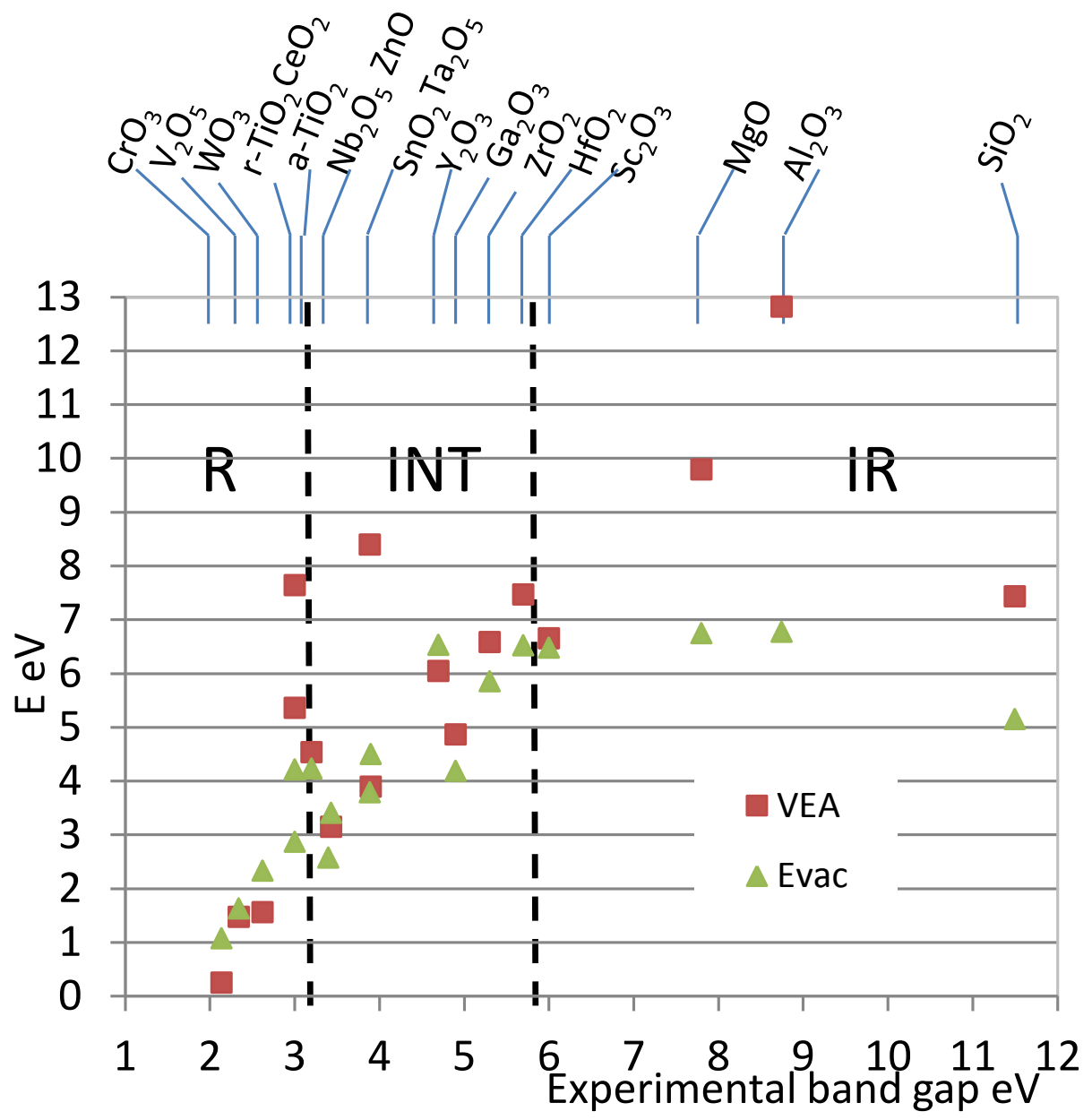

Figure 5: calculated oxygen vacancy formation $\left(\mathrm{E}_{\mathrm{vac}}\left(1 / 2 \mathrm{O}_{2}\right)\right)$ energy and vertical electron affinity (VEA) vs. experimental band gap for the series of oxides. 
The main reason for the different ordering is the relaxation occurring in the defective system. The ordering obtained from the values of the electronic gap or VEA (Table 5, line 5) reflects an intrinsic property while that on the energies of formation of the vacancies takes into account a geometric and electronic rearrangement. This occurs in the IR group for silica, in the R group for gallia and tantalum pentoxide making the energy of formation easier. Then, there is the formation of a bond between the cations in the vicinity of the vacancy. The structures possessing terminal oxygen atoms, such as vanadia and chromia, also exhibit a strong structural and $\mathrm{M}-\mathrm{O}$ bonding rearrangement accounting for a decrease in the $E_{v a c}$ values. The band gap criterion leads to a different ranking (Table 5, line 6).

Electronic states of group IR are singlet and diamagnetic. That of the group INT is singlet antiferromagnetic; this appears, in the end, as the main difference with the group IR. $\mathrm{Y}_{2} \mathrm{O}_{3}$ shows a mixed distribution with both localization in the cavity and on the atoms neighbouring the cavity. The states for the group $\mathrm{R}$ show two unpaired electrons, antiferromagnetic or triplet. As expected, localization on the metal cation is found for the group R.

The localization of the electrons as an indication of the reducibility shows surprises. There are two exceptions, tin dioxide and gallia as discussed in the previous sections.

Finally the perception of an F-center is modified by many cases. There are unclear situations with localization both in the cavity and on the neighbouring atoms. In several cases, the distance between two cations indicates the formation of a metal-metal bond. The electron density at the center of the bond might be interpreted as a formation of a covalent bond or as that of an F-center. When electrons are localized in $V_{3}$ cavities, the localization contour is not spherical, but has a flat triangular shape. Contribution to the F-center of the two spin-orbitals of same energy but opposite spins may show random distribution even though the resulting density has more symmetry. 


\section{Conclusions}

The reducible character of a series of metal oxides with the metal in its higher oxidation state has been analyzed as regards geometric parameters (crystalline phase, atomic coordination, reconstruction) and chemical descriptors (metal oxidation state, band gap, vertical electron affinity, oxygen vacancy formation energy, electron localization). All the descriptors used are sensitive to the computational setting and the results can be considered as semi-quantitative. They allow the comparison between several structures and provide a comprehensive picture of the energetics and electronic features of the reduction process or the reduced systems. Despite their limitations, general trends are well represented, especially as regards extreme cases like irreducible $\mathrm{MgO}, \mathrm{SiO}_{2}$ or reducible $\mathrm{CrO}_{3}, \mathrm{TiO}_{2}$. Moreover, the combination of several descriptors reveals the mechanisms of reduction and allows characterizing intermediate behaviors.

Oxides under consideration can thus be classified with respect to their reducibility by different criteria. As a general rule, a low oxidation state of the metal in the oxide, and a high coordination are associated to a low reducibility. According to the energies of oxygen vacancy formation, electronic structure and character of reduction electrons localization, $\mathrm{MgO}, \mathrm{SiO}_{2}$ and $\mathrm{Al}_{2} \mathrm{O}_{3}$ are hardly reducible and are characterized by high band gap, high electron affinity, high oxygen vacancy formation energy, localization of electrons in the position of the oxygen vacancy and a singlet diamagnetic electronic state. On the other side, $\mathrm{CrO}_{3}, \mathrm{WO}_{3}, \mathrm{CeO}_{2}, \mathrm{TiO}_{2}, \mathrm{~V}_{2} \mathrm{O}_{5}$ are reducible and characterized by high cation oxidation states, low band gap, low electron affinity, low oxygen vacancy formation energy, localization of the reduction electrons in the metal sites and open-shell electronic states. Intermediate or ambivalent behavior is found for $\mathrm{ZrO}_{2}, \mathrm{HfO}_{2}, \mathrm{ZnO}, \mathrm{Y}_{2} \mathrm{O}_{3}, \beta-\mathrm{Ga}_{2} \mathrm{O}_{3}, \mathrm{Nb}_{2} \mathrm{O}_{5}, \mathrm{Ta}_{2} \mathrm{O}_{5}$ and $\mathrm{SnO}_{2}$. For these oxides a mixed behavior is observed and is associated to metals with an electronic structure allowing reduction under certain conditions. A mechanism to stabilize reduced systems in these intermediate cases may be to form metal-metal bonds such as in $\mathrm{Ga}_{2} \mathrm{O}_{3}$. Interestingly, besides the electronic properties of the metal, 
the structural relaxation is found to play a key role stabilizing reduced (oxygen defective) crystals as in $\mathrm{Ta}_{2} \mathrm{O}_{5}$.

\section{Acknowledgements}

Authors acknowledge B. Diawara for the Modelview program and Scienomics for the MAPS courtesy license. This work was performed using HPC resources from GENCI- CINES/IDRIS (Grants 2013x2013082131, 2014- x2014082131, 2015- x2015082131, 2016- x2016082131, 2017- x2012082131), the CCRE-DSI of Université P. M. Curie and KAUST HPC supercomputer Shaheen under project k1087. This work has been carried out in the frame of the COST action CM1104 Reducible metal oxides. 


\section{References}

1. Helali Z, Markovits A, Minot C, Abderrabba M (2012) First Row Transition Metal Atoms Adsorption on Rutile $\mathrm{TiO}_{2}(110)$ Surface. Struct Chem 23:1309

2. Helali Z, Markovits A, Minot C, Abderrabba M (2014) Metal atom adsorption on a defective TiO $2-x$ support. Chemical Physics Letters 594:23-29.

3. Bond GC, Tahir SF (1991) Vanadium oxide monolayer catalysts Preparation, characterization and catalytic activity. Applied catalysis $71(1): 1-31$

4. Deo G, Wachs IE, Haber J (1994) Supported Vanadium Oxide Catalysts:'Molecular Structural Characterization and Reactivity Properties. Critical Rev Surf Chem 4:141

5. Weckhuysen BM, Keller DE (2003) Chemistry, spectroscopy and the role of supported vanadium oxides in heterogeneous catalysis. Catalysis Today 78 (1):25-46

6. Summers JC, Ausen SA (1979) Interaction of cerium oxide with noble metals. Journal of Catalysis 58 (1):131-143.

7. Tauster SJ, Fung SC, Baker RTK, Horsley JA (1981) Strong interactions in supported metal catalysts. Science 211 (4487):1121-1125

8. Tauster SJ, Fung SC, Garten RL (1978) Strong metal-support interactions - group 8 noble-metals supported on $\mathrm{TiO}_{2}$. Journal of the American Chemical Society 100 (1):170-175

9. Sousa C, Illas F (1994) lonic-covalent transition in titanium oxides. Phys Rev B Condens Matter 50:13974-13980.

10. Sanderson RT (1983) Electronegativity and bond energy. Journal of the American Chemical Society 105 (8):22592261. doi:10.1021/ja00346a026

11. Hill YD, Huang Y, Ast T, Freiser BS (1997) Study of the Gas-phase Chemistry of $Y^{2+}$ with Small Alkanes. Rapid Communications in Mass Spectrometry 11 (1):148-154. doi:10.1002/(SICI)1097-0231(19970115)11:1<148::AIDRCM819>3.0.CO;2-5

12. Sharma TC, Sharma SC, Bhandari KS (1984) Polarographic behaviour of yttrium. Analyst 109 (12):1615-1616. doi:10.1039/an9840901615

13. Beltrán A, Andrés J, Calatayud M, Martins JBL (2001) Theoretical study of ZnO (1 $\left.\begin{array}{lll}1 & 1 & 0\end{array}\right)$ and Cu/ZnO $\left(\begin{array}{llll}1 & 0 & 1 & 0\end{array}\right)$ surfaces. Chemical Physics Letters 338 (4-6):224-230.

14. Calatayud M, Markovits A, Menetrey M, Mguig B, Minot C (2003) Adsorption on perfect and reduced surfaces of metal oxides. Catalysis Today 85 (2-4):125-143.

15. Calatayud M, Markovits A, Minot C (2004) Electron-count control on adsorption upon reducible and irreducible clean metal-oxide surfaces. Catalysis Today 89 (3):269-278.

16. Calatayud M, Markovits A, Minot C (2008) Periodic DFT studies on adsorption and reactivity on metal and metal oxide surfaces. In: Basiuk VA, Ugliengo P (eds) Chapter 11 of the American Scientific Publisher book "Quantum Chemical Calculations of Surfaces and Interfaces of Materials" UK, pp 183-210

17. Ganduglia-Pirovano MV, Hofmann A, Sauer J (2007) Oxygen vacancies in transition metal and rare earth oxides: Current state of understanding and remaining challenges. Surface Science Reports 62 (6):219-270.

18. Menetrey M, Markovits A, Minot C (2003) Reactivity of a reduced metal oxide surface: hydrogen, water and carbon monoxide adsorption on oxygen defective rutile $\mathrm{TiO}_{2}(110)$. Surface Science 524 (1-3):49-62.

19. Calatayud $\mathrm{M}$, Minot $\mathrm{C}$ (2006) Reactivity of the $\mathrm{V}_{2} \mathrm{O}_{5}-\mathrm{TiO}_{2}$-anatase catalyst: role of the oxygen sites. Topics in Catalysis 41 (1-4):17-26. doi:10.1007/s11244-006-0090-x

20. Calatayud M, Minot C (2009) Is There a Nanosize for the Activity of $\mathrm{TiO}_{2}$ Compounds? Journal of Physical Chemistry C 113 (28):12186-12194. doi:10.1021/jp901465q

21. Calatayud M, Tielens F, De Proft F (2008) Reactivity of gas-phase, crystal and supported $\mathrm{V}_{2} \mathrm{O}_{5}$ systems studied using density functional theory based reactivity indices. Chemical Physics Letters 456 (1-3):59-63. doi:10.1016/j.cplett.2008.03.007

22. Perdew JP, Burke K, Ernzerhof M (1996) Generalized Gradient Approximation Made Simple. Physical Review Letters 77 (18):3865-3868

23. Blöchl PE (1994) Projector augmented-wave method. Physical Review B 50 (24):17953-17979

24. Kresse G, Joubert D (1999) From ultrasoft pseudopotentials to the projector augmented-wave method. Physical Review B 59 (3):1758-1775

25. Calatayud M (2017). https://sites.google.com/site/calatayudantonino/k/oxides.

26. Kresse G, Furthmüller J (1996) Efficient iterative schemes for ab initio total-energy calculations using a planewave basis set. Physical Review B 54 (16):11169-11186

27. Kresse G, Furthmüller J (1996) Efficiency of ab-initio total energy calculations for metals and semiconductors using a plane-wave basis set. Computational Materials Science 6 (1):15-50 
28. Kresse G, Hafner J (1993) Ab initio molecular dynamics for open-shell transition metals. Physical Review B 48 (17):13115-13118

29. Kresse G, Hafner J (1994) Norm-conserving and ultrasoft pseudopotentials for first-row and transition elements. Journal of Physics: Condensed Matter 6 (40):8245

30. Momma K, Izumi F (2008) VESTA: a three-dimensional visualization system for electronic and structural analysis. Journal of Applied Crystallography 41 (3):653-658. doi:doi:10.1107/S0021889808012016

31. Morgan BJ, Watson GW (2007) A DFT+U description of oxygen vacancies at the $\mathrm{TiO}_{2}$ rutile (110) surface. Surface Science 601 (21):5034-5041

32. Morgan BJ, Watson GW (2009) A Density Functional Theory + U Study of Oxygen Vacancy Formation at the (110), (100), (101), and (001) Surfaces of Rutile $\mathrm{TiO}_{2}$. The Journal of Physical Chemistry C 113 (17):7322-7328. doi:10.1021/jp811288n

33. Jedidi A, Markovits A, Minot C, Bouzriba S, Abderraba M (2010) Modeling Localized Photoinduced Electrons in Rutile- $\mathrm{TiO}_{2}$ Using Periodic DFT+U Methodology Langmuir 26 (21):16232-16238. doi:10.1021/la101359m

34. Morgan BJ, Watson GW (2010) Intrinsic n-type Defect Formation in $\mathrm{TiO}_{2}$ : A Comparison of Rutile and Anatase from GGA plus U Calculations. Journal of Physical Chemistry C 114 (5):2321-2328. doi:10.1021/jp9088047

35. Scanlon DO, Walsh A, Morgan BJ, Watson GW (2008) An ab initio study of reduction of $\mathrm{V}_{2} \mathrm{O}_{5}$ through the formation of oxygen vacancies and Li intercalation. Journal of Physical Chemistry C 112 (26):9903-9911. doi:10.1021/jp711334f

36. Laubach S, Schmidt PC, Thissen A, Fernandez-Madrigal FJ, Wu QH, Jaegermann W, Klemm M, Horn S (2007) Theoretical and experimental determination of the electronic structure of $\mathrm{V}_{2} \mathrm{O}_{5}$, reduced $\mathrm{V}_{2} \mathrm{O}_{5-x}$ and sodium intercalated $\mathrm{NaV}_{2} \mathrm{O}_{5}$. Physical Chemistry Chemical Physics 9 (20):2564-2576. doi:10.1039/b612489e

37. Fabris S, de Gironcoli S, Baroni S, Vicario G, Balducci G (2005) Taming multiple valency with density functionals: A case study of defective ceria. Physical Review B 71 (4):041102

38. Cococcioni $M$, de Gironcoli S (2005) Linear response approach to the calculation of the effective interaction parameters in the LDA+U method. Physical Review B 71 (3):035105

39. Fabris S, de Gironcoli S, Baroni S, Vicario G, Balducci G (2005) Reply to Comment on Taming multiple valency with density functionals: A case study of defective ceria. Physical Review B 72 (23):237102

40. Kresse G, Blaha P, Da Silva JLF, Ganduglia-Pirovano MV (2005) Comment on "Taming multiple valency with density functionals: A case study of defective ceria". Physical Review B 72 (23):237101

41. Fabris S, Vicario G, Balducci G, de Gironcoli S, Baroni S (2005) Electronic and Atomistic Structures of Clean and Reduced Ceria Surfaces. The Journal of Physical Chemistry B 109 (48):22860-22867. doi:10.1021/jp0511698

42. Nolan M, Grigoleit S, Sayle DC, Parker SC, Watson GW (2005) Density functional theory studies of the structure and electronic structure of pure and defective low index surfaces of ceria. Surface Science 576:217-229

43. Jiang $\mathrm{Y}$, Adams JB, van Schilfgaarde $\mathrm{M}$ (2005) Density-functional calculation of $\mathrm{CeO}_{2}$ surfaces and prediction of effects of oxygen partial pressure and temperature on stabilities. The Journal of Chemical Physics 123 (6):064701064709

44. Jiang Y, Adams JB, van Schilfgaarde M, Sharma R, Crozier PA (2005) Theoretical study of environmental dependence of oxygen vacancy formation in $\mathrm{CeO}_{2}$. Applied Physics Letters 87 (14):141917. doi:141917 $10.1063 / 1.2084324$

45. Loschen C, Carrasco J, Neyman KM, Illas F (2007) First-principles LDA+U and GGA+U study of cerium oxides: Dependence on the effective $U$ parameter. Physical Review B 75 (3):035115

46. Ivanov MV, Perevalov TV, Aliev VS, Gritsenko VA, Kaichev VV (2011) Electronic structure of delta $-\mathrm{Ta}_{2} \mathrm{O}_{5}$ with oxygen vacancy: ab initio calculations and comparison with experiment. Journal of Applied Physics 110 (2):024115024115

47. Kaczkowski J (2012) Electronic Structure of Some Wurtzite Semiconductors: Hybrid Functionals vs. Ab Initio Many Body Calculations. Acta Physica Polonica A 121:1142

48. Lany S (2008) Semiconductor thermochemistry in density functional calculations. Physical Review B 78 (24):245207

49. Erhart P, Albe K, Klein A (2006) First-principles study of intrinsic point defects in ZnO: Role of band structure, volume relaxation, and finite-size effects. Physical Review B 73 (20):205203

50. Garza AJ, Scuseria GE (2016) Predicting Band Gaps with Hybrid Density Functionals. The Journal of Physical Chemistry Letters 7 (20):4165-4170. doi:10.1021/acs.jpclett.6b01807

51. Heyd J, Scuseria GE, Ernzerhof M (2003) Hybrid functionals based on a screened Coulomb potential. The Journal of Chemical Physics 118 (18):8207-8215. 
52. Heyd J, Scuseria GE, Ernzerhof M (2006) Erratum: "Hybrid functionals based on a screened Coulomb potential" [J. Chem. Phys.118, 8207 (2003)]. The Journal of Chemical Physics 124 (21):219906.

53. Henderson TM, Paier J, Scuseria GE (2011) Accurate treatment of solids with the HSE screened hybrid. physica status solidi (b) 248 (4):767-774. doi:10.1002/pssb.201046303

54. Lucero MJ, Henderson TM, Scuseria GE (2012) Improved semiconductor lattice parameters and band gaps from a middle-range screened hybrid exchange functional. Journal of Physics: Condensed Matter 24 (14):145504

55. Brix P, Herzberg G (1953) The Dissociation Energy of Oxygen. The Journal of Chemical Physics 21 (12):2240-2240

56. Gray HB (1994) Chemical Bonds: An Introduction to Atomic and Molecular Structure. University Science Books, Mill Valley, California

57. Hammer B, Hansen LB, Norskov JK (1999) Improved adsorption energetics within density-functional theory using revised Perdew-Burke-Ernzerhof functionals. Physical Review B 59 (11):7413-7421

58. Wang L, Maxisch T, Ceder G (2006) Oxidation energies of transition metal oxides within the GGA+U framework. Physical Review B 73 (19):195107

59. Scienomics (2004-2015) Introduction to MAPS. Paris, France

60. Finazzi E, Di Valentin C, Pacchioni G, Selloni A (2008) Excess electron states in reduced bulk anatase $\mathrm{TiO}_{2}$ : Comparison of standard GGA, GGA plus U, and hybrid DFT calculations. Journal of Chemical Physics 129 (15):154113. doi:154113 10.1063/1.2996362

61. Janotti A, Varley JB, Rinke P, Umezawa N, Kresse G, Van de Walle CG (2010) Hybrid functional studies of the oxygen vacancy in $\mathrm{TiO}_{2}$. Physical Review B 81 (8):085212. doi:085212 10.1103/PhysRevB.81.085212

62. Angenault J (2001) Symetrie et Structure. Vuibert,

63. Hannic F, Hartmanova $\mathrm{M}$ (1984) Real structure of undopped $\mathrm{Y}_{2} \mathrm{O}_{3}$ Single cristal Acta Cryst B40: 76-82

64. http://en.wikipedia.org/wiki/Rutile

65. http://www.mindat.org/min-213.html

66. Garcia JC, Scolfaro LMR, Lino AT, Freire VN, Farias GA, Silva CC, Alves HWL, Rodrigues SCP, da Silva Jr EF (2006) Structural, electronic, and optical properties of $\mathrm{ZrO} 2$ from ab initio calculations. Journal of Applied Physics 100 (10):104103

67. Hann RE, Suitch PR, Pentecost JL (1985) Monoclinic Crystal Structures of $\mathrm{ZrO}_{2}$ and $\mathrm{HfO}_{2}$ Refined from X-ray Powder Diffraction Data. Journal of the American Ceramic Society 68 (10):C-285-C-286. doi:10.1111/j.11512916.1985.tb11534.x

68. Gerward L, Olsen JS, Petit L, Vaitheeswaran G, Svane KVA (2005) Bulk modulus of $\mathrm{CeO}_{2}$ and $\mathrm{PrO}_{2}-\mathrm{An}$ experimental and theoretical study. J Alloys Comp 40056

69. Enjalbert R, Galy J (1986) A refinement of the structure of $\mathrm{V}_{2} \mathrm{O}_{5}$. Acta Cryst C 421467

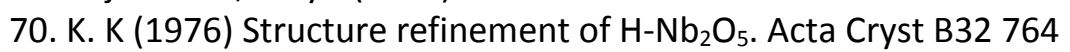

71. Fukumoto A, Miwa K (1997) Prediction of hexagonal $\mathrm{Ta}_{2} \mathrm{O}_{5}$ structure by first-principles calculations. Physical Review B (Condensed Matter) 55:11155-11160

72. Jalili $H$ (2008) Materials physics of half-metallic magnetic oxide films by Pulsed Laser Deposition: Controlling the crystal structure and near-surface properties of $\mathrm{Sr}_{2} \mathrm{FeMoO}_{6}$ and $\mathrm{CrO}_{2}$ films University of Waterloo, Waterloo, Ontario, Canada, 2008

73. Sawai Y, Hazu K, Chichibu SF (2010) Surface stoichiometry and activity control for atomically smooth low dislocation density $\mathrm{ZnO}$ and pseudomorphic MgZnO epitaxy on a Zn-polar ZnO substrate by the helicon-waveexcited-plasma sputtering epitaxy method. Journal of Applied Physics 108 (6):063541. doi:10.1063/1.3485600

74. WO3: transport properties, monoclinic phase (2000). In: Madelung O, Rössler U, Schulz M (eds) NonTetrahedrally Bonded Binary Compounds II. Springer Berlin Heidelberg, Berlin, Heidelberg, pp 1-8. doi:10.1007/10681735_680

75. Lassner EW-DS (1999) Tungsten: Properties, Chemistry, Technology of the Element, Alloys, and Chemical Compounds. New York: Kluwer Academic,

76. Saki K, Kenji T, Nobuo I (2008) Structural Evolution of Corundum at High Temperatures. Japanese Journal of Applied Physics 47 (1S):616

77. Geller S (1960) Crystal Structure of $\beta-\mathrm{Ga}_{2} \mathrm{O}_{3}$. The Journal of Chemical Physics 33 (3):676-684. doi:10.1063/1.1731237

78. Haiying He RO, Miguel A. Blanco,and Ravindra Pandey (2006) First-principles study of the structural, electronic, and optical properties of Ga2O3 in its monoclinic and hexagonal phases. Physical Review B 74:195123 doi:: 10.1103/PhysRevB.74.195123

79. Lager GA, Jorgensen JD, Rotella FJ (1982) Crystal structure and thermal expansion of $\alpha$-quartz SiO2 at low temperatures. Journal of Applied Physics 53 (10):6751-6756. doi:10.1063/1.330062 
80. Haines J, Léger JM (1997) X-ray diffraction study of the phase transitions and structural evolution of tin dioxide at high pressure:ffRelationships between structure types and implications for other rutile-type dioxides. Physical Review B 55 (17):11144-11154

81. Postnikov AV, Entel $P$, Ordejon $P(2002) \mathrm{SnO}_{2}$ : Bulk and surface simulations by an ab initio numerical local orbitals method. Phase Transitions: A Multinational Journal 75 (1-2):143-149

82. Kisi EH, Elcombe MM (1989) U parameters for the Wurtzite Structure of ZnS and ZnO using Powder Neutron Diffraction. acta cristallographica C 45:1867

83. Orita M, Ohta $\mathrm{H}$, Hirano $\mathrm{M}$, Hosono H (2000) Deep-ultraviolet transparent conductive beta- $\mathrm{Ga}_{2} \mathrm{O}_{3}$ thin films. Applied Physics Letters 77 (25):4166-4168

84. Deml AM, Holder AM, O'Hayre RP, Musgrave CB, Stevanović V (2015) Intrinsic Material Properties Dictating Oxygen Vacancy Formation Energetics in Metal Oxides. The Journal of Physical Chemistry Letters 6 (10):1948-1953. doi:10.1021/acs.jpclett.5b00710

85. Di Valentin C, Pacchioni G (2014) Spectroscopic Properties of Doped and Defective Semiconducting Oxides from Hybrid Density Functional Calculations. Accounts of Chemical Research 47 (11):3233-3241. doi:10.1021/ar4002944

86. Jun C, Lin L, Lu T, Yong L (1999) Electronic structure of F, F+-center in MgO. European Physical Journal B 9 (4):593598

87. Zhukovskii YF, Kotomin EA, Evarestov RA, Ellis DE (2007) Periodic models in quantum chemical Simulations of $F$ Centers in crystalline metal oxides. International Journal of Quantum Chemistry 107 (14):2956-2985. doi:10.1002/qua.21483

88. Kantorovich LN, Holender JM, Gillan MJ (1995) The energetics and electronic structure of defective and irregular surfaces on MgO. Surface Science 343 (3):221-239

89. Klein BM, Pickett WE, Boyer LL (1987) Theory of F-centers in the alkaline earth oxides MgO and CaO. Physical Review B 35 (11):5802-5815

90. Safa O. Kasap PC (2006) Springer handbook of electronic and photonic materials.

91. Morkoç H, Özgür Ü (2009) Zinc Oxide: Fundamentals, Materials and Device Technology. Wiley-VCH Verlag GmbH \& Co. KGaA, Weinheim

92. Leiter F, Alves H, Pfisterer D, Romanov NG, Hofmann DM, Meyer BK (2003) Oxygen vacancies in ZnO. Physica B: Condensed Matter 340-342 (0):201-204.

93. Smith JM, Vehse WE (1970) ESR of electron irradiated ZnO confirmation of the F+ center. Physics Letters A 31 (3):147-148.

94. Soriano V, Galland D (1976) Photosensitivity of the EPR spectrum of the $\mathrm{F}^{+}$center in ZnO. physica status solidi (b) $77(2): 739-743$.

95. van Craeynest F, Maenhout-Van Der Vorst W, Dekeyser W (1965) Interpretation of the Yellow Colour of Heat Treated ZnO Powder. physica status solidi (b) 8 (3):841-846.

96. Wei WF (1977) $F^{+}$center in ZnO. Physical Review B 15 (4):2250-2253

97. Himmel H-J, Manceron L, Downs AJ, Pullumbi P (2002) Formation and Characterization of the Gallium and Indium Subhydride Molecules $\mathrm{Ga}_{2} \mathrm{H}_{2}$ and $\ln _{2} \mathrm{H}_{2}$ : A Matrix Isolation Study. Journal of the American Chemical Society 124 (16):4448-4457.

98. Jegier JA, Gladfelter WL (2000) The use of aluminum and gallium hydrides in materials science. Coordination Chemistry Reviews 206-207:631-650. 


\title{
Scaling Reducibility of Metal Oxides
}

\author{
Z. Helali, A. Jedidi, O. A. Syzgantseva, M. Calatayud, C. Minot
}

\section{Supporting Information}

Table S1: Band gaps in oxides

Table S2. Formation energies of oxygen vacancies, $E_{v a c}$, in oxides 


\begin{tabular}{|c|c|c|c|c|c|c|}
\hline \multirow{2}{*}{ Oxide } & \multicolumn{3}{|c|}{ Gaps (present work) } & \multicolumn{2}{|c|}{ Gaps, literature data } & \multirow{2}{*}{ Group } \\
\hline & PBE & PBE+U & B3LYP & Calculated & Experimental & \\
\hline $\mathrm{Al}_{2} \mathrm{O}_{3}$ & 6.2 & & 8.9 & $\begin{array}{c}5.9[1] \\
6.2[2] \\
6.33[3]\end{array}$ & $\begin{array}{c}7-8[4] \\
8.75[5] \\
8.8[6] \\
10.8[7]\end{array}$ & IR3 \\
\hline $\mathrm{SiO}_{2}$ & 5.9 & & 7.82 & $\begin{array}{c}8.9[8] \\
10.4[9]\end{array}$ & $\begin{array}{c}11.5[10] \\
5.6-11.5[9]\end{array}$ & IR4 \\
\hline $\mathrm{MgO}$ & 4.77 & & 7.23 & $4.8[11]$ & $7.8[12]$ & IR2 \\
\hline $\mathrm{Y}_{2} \mathrm{O}_{3}$ & 3.93 & & 6.15 & $\begin{array}{c}4.54[13] \\
5.7[14]\end{array}$ & $4.7[15]$ & IR3 \\
\hline $\mathrm{Sc}_{2} \mathrm{O}_{3}$ & 3.69 & & 5.76 & $6[16]$ & $6-6.3[17]$ & IR3 \\
\hline $\mathrm{HfO}_{2}$ & 4.00 & & 5.80 & $4.12[18]$ & 5.7 [19] & INT \\
\hline $\mathrm{ZrO}_{2}$ & 3.47 & & 5.27 & $\begin{array}{c}3.41[20] \\
5.42[21] \\
5.7[22]\end{array}$ & $5.3[23]$ & INT \\
\hline$\beta-\mathrm{Ga}_{2} \mathrm{O}_{3}$ & 2.37 & & 4.64 & $4.87[24]$ & $\begin{array}{c}4.9[25] \\
4.4-4.8[26,17,27]\end{array}$ & R3 \\
\hline $\mathrm{TiO}_{2}$ anatase & 2.05 & 2.64 & 3.8 & $2.05[28]$ & $3.2[29]$ & R4 \\
\hline $\mathrm{CeO}_{2}$ & 1.97 & 2.25 & 3.59 & $1.8[30]$ & $3.0[30]$ & R4 \\
\hline $\mathrm{Nb}_{2} \mathrm{O}_{5}$ & 1.92 & & 1.97 & $1.6[31]$ & 3.4 [32] & R5 \\
\hline $\mathrm{SnO}_{2}$ & 1.89 & 2.23 & 3.7 & $\begin{array}{c}3.7-3.89[33] \\
3.8[34] 3.4[35] \\
0.95[36] \\
1.65[36]\end{array}$ & $\begin{array}{c}2.25-4.3[33] \\
3.5-4.0[38] \\
3.89[37]\end{array}$ & R4 \\
\hline
\end{tabular}




\begin{tabular}{|c|c|c|c|c|c|c|}
\hline & & & & $1.4[37]$ & & \\
\hline $\mathrm{TiO}_{2}$ rutile & 1.81 & 2.41 & 3.44 & 1.77 [39] & 3.0 [29] & R4 \\
\hline $\mathrm{Ta}_{2} \mathrm{O}_{5}$ & 1.80 & & 3.86 & $\begin{array}{c}1.06[40] \\
1.31[41] \\
0.96-1.96[42]\end{array}$ & $\begin{array}{c}3.9[43] \\
3.75[44] \\
4.2[45,46]\end{array}$ & R5 \\
\hline$\alpha-\mathrm{V}_{2} \mathrm{O}_{5}$ & 1.7 & 1.9 & 3.32 & $2.3[47]$ & $\begin{array}{c}2.0-2.1[48] \\
2.34[49,50] \\
2.35[51]\end{array}$ & R5 \\
\hline $\mathrm{CrO}_{3}$ & 1.42 & 1.6 & 3.49 & $\begin{array}{c}2.25[52,53] \\
1.8[54]\end{array}$ & $2.14[55]$ & R6 \\
\hline $\mathrm{WO}_{3}$ & 1.17 & 1.36 & 2.63 & $\begin{array}{c}1.6-2.4[56] \\
0.9-1.58[57]\end{array}$ & $\begin{array}{l}2.62[58] \\
2.77[59]\end{array}$ & R6 \\
\hline $\mathrm{ZnO}$ & 0.9 & 1.2 & 2.94 & $\begin{array}{c}0.79[60] \\
0.77[61] \\
0.93[62] \\
1.15[63] \\
3.2[64]\end{array}$ & $3.43[60,65]$ & IR2 \\
\hline
\end{tabular}

Table S1. Band gaps in oxides under consideration ranked by decreasing values: a: gap found in the present work; b: theoretical gap found by comparable methods; c: experimental gap (Note that the optical band gap is larger than the HOMO-LUMO gap when selection rules forbid the lowest excitation). 


\begin{tabular}{|c|c|c|c|c|c|c|}
\hline Oxide/ phase & Group & $\begin{array}{c}\text { Concentration of } \\
\text { defects }\end{array}$ & $\begin{array}{l}\text { Type of } \\
\text { vacancy }\end{array}$ & $E_{\mathrm{vac}}(0) \mathrm{eV}$ & $E_{\mathrm{vac}}\left(1 / 2 \mathrm{O}_{2}\right) \mathrm{eV}$ & Spin state \\
\hline $\mathrm{Al}_{2} \mathrm{O}_{3}$ & IR3 & $1 / 72 *$ & $\mathrm{~V}_{4}$ & 9.80 & 6.77 & Singlet diamagnetic \\
\hline $\mathrm{MgO}$ & IR2 & $1 / 32 *$ & $V_{6}$ & $\begin{array}{c}9.79 \\
10.08[66]\end{array}$ & 6.75 & Singlet diamagnetic \\
\hline $\mathrm{Y}_{2} \mathrm{O}_{3}$ & IR3 & $1 / 48 *$ & $\mathrm{~V}_{4}$ & 9.57 & 6.53 & Singlet diamagnetic \\
\hline $\mathrm{Sc}_{2} \mathrm{O}_{3}$ & IR3 & $1 / 48 *$ & $\mathrm{~V}_{4}$ & 9.52 & 6.48 & Singlet diamagnetic \\
\hline \multirow{2}{*}{$\mathrm{HfO}_{2}$} & \multirow[t]{2}{*}{ INT4 } & $1 / 64$ & $V_{3}$ & $\begin{array}{c}9.55 \\
9.36[18]\end{array}$ & $\begin{array}{c}6.52 \\
6.42[18]\end{array}$ & Singlet diamagnetic \\
\hline & & $1 / 64 *$ & $\mathrm{~V}_{4}$ & 9.43 & 6.39 & Singlet diamagnetic \\
\hline \multirow[b]{2}{*}{$\mathrm{ZrO}_{2}$} & \multirow[b]{2}{*}{ INT4 } & $1 / 64$ & $V_{3}$ & $\begin{array}{c}8.96 \\
8.90[20]\end{array}$ & $\begin{array}{c}5.92 \\
5.96[20]\end{array}$ & Singlet antiferromagnetic \\
\hline & & $1 / 64 *$ & $\mathrm{~V}_{4}$ & $\begin{array}{c}8.89 \\
8.88[20]\end{array}$ & $\begin{array}{c}5.85 \\
5.94[20] \\
5.92[67]\end{array}$ & Singlet antiferromagnetic \\
\hline $\mathrm{SiO}_{2}$ & IR4 & $1 / 48 *$ & $V_{2}$ & 8.18 & 5.15 & Singlet diamagnetic \\
\hline \multirow{3}{*}{$\mathrm{TiO}_{2}$ rutile } & \multirow{3}{*}{ R4 } & $1 / 32$ & $V_{3}$ & $\begin{array}{c}7.87 \\
7.41[34] \\
\end{array}$ & 4.84 & Singlet antiferromagnetic \\
\hline & & $1 / 48$ & $V_{3}$ & 7.24 & 4.21 & Singlet antiferromagnetic \\
\hline & & $1 / 64$ & $V_{3}$ & 7.24 & 4.21 & Singlet antiferromagnetic \\
\hline
\end{tabular}




\begin{tabular}{|c|c|c|c|c|c|c|}
\hline & & $1 / 180 *$ & $V_{3}$ & 6.72 & $\begin{array}{c}3.69 \\
4.05[67]\end{array}$ & Singlet antiferromagnetic \\
\hline \multirow{2}{*}{$\mathrm{TiO}_{2}$ anatase } & \multirow{2}{*}{ R4 } & $1 / 32$ & $V_{3}$ & $8.23[34]$ & & Singlet antiferromagnetic \\
\hline & & $1 / 72 *$ & $V_{3}$ & 7.26 & 4.23 & Singlet antiferromagnetic \\
\hline \multirow{3}{*}{$\delta^{\prime}-\mathrm{Ta}_{2} \mathrm{O}_{5}$} & \multirow{3}{*}{ R5 } & $1 / 80$ & $V_{3 h}$ & 7.53 & 4.50 & Singlet diamagnetic \\
\hline & & & $\mathrm{V}_{2 \mathrm{~h}}$ & 8.13 & 5.10 & Singlet diamagnetic \\
\hline & & & $V_{2 v}$ & 8.73 & 5.70 & Singlet diamagnetic \\
\hline \multirow{2}{*}{$\mathrm{SnO}_{2}$} & \multirow{2}{*}{ R4 } & $1 / 32$ & $V_{3}$ & $6.99[34]$ & & Singlet diamagnetic \\
\hline & & $1 / 48 *$ & $\mathrm{~V}_{3}$ & 6.87 & 3.84 & Singlet diamagnetic \\
\hline \multirow{3}{*}{$\beta-\mathrm{Ga}_{2} \mathrm{O}_{3}$} & R3 & $1 / 72 *$ & $V_{3 g}$ & 6.82 & 3.79 & Singlet diamagnetic \\
\hline & R3 & $1 / 72$ & $V_{3 v}$ & 7.23 & 4.19 & Singlet diamagnetic \\
\hline & R3 & $1 / 72$ & $\mathrm{~V}_{4}$ & 7.45 & 4.42 & Singlet diamagnetic \\
\hline $\mathrm{ZnO}$ & IR2 & $1 / 36$ & $\mathrm{~V}_{4}$ & 6.45 & 3.41 & Singlet diamagnetic \\
\hline $\mathrm{CeO}_{2}$ & R4 & $1 / 64 *$ & $\mathrm{~V}_{4}$ & 5.91 & $\begin{array}{c}2.87 \\
3.62[68]\end{array}$ & Triplet \\
\hline $\mathrm{CeO}_{2}$ & R4 & $1 / 90$ & $\mathrm{~V}_{1}$ & & $1.46[47]$ & Triplet \\
\hline $\mathrm{V}_{2} \mathrm{O}_{5}$ terminal & R5 & $1 / 60 *$ & $\mathrm{~V}_{1}$ & 4.66 & 1.63 & Singlet antiferromagnetic \\
\hline \multirow{2}{*}{$\mathrm{V}_{2} \mathrm{O}_{5}$ bridging } & \multirow{2}{*}{ R5 } & $1 / 60$ & $V_{2}$ & 6.45 & 3.42 & Singlet antiferromagnetic \\
\hline & & $1 / 90$ & $V_{2}$ & & $3.15[47]$ & Triplet \\
\hline \multirow{2}{*}{$\mathrm{V}_{2} \mathrm{O}_{5}$ three-fold } & \multirow{2}{*}{ R5 } & $1 / 60$ & $V_{3}$ & 6.56 & 3.52 & Singlet antiferromagnetic \\
\hline & & $1 / 90$ & $V_{3}$ & & $3.25[47]$ & Triplet \\
\hline
\end{tabular}




\begin{tabular}{|c|c|c|c|c|c|c|}
\hline $\mathrm{Nb}_{2} \mathrm{O}_{5}$ & R5 & $1 / 140 *$ & $V_{2}$ & 5.60 & 2.57 & Singlet \\
\hline $\mathrm{WO}_{3}$ & R6 & $1 / 192$ & $V_{2 v}$ & 5.36 & 2.33 & Singlet \\
\hline $\mathrm{WO}_{3}$ & R6 & $1 / 16$ & $\mathrm{~V}_{2 \mathrm{v}}$ & $5.34-4.51[69]$ & & Singlet \\
\hline $\mathrm{CrO}_{3}$ vertical & R6 & $1 / 48 *$ & $\mathrm{~V}_{1}$ & 4.11 & 1.07 & Triplet \\
\hline $\mathrm{CrO}_{3}$ horizontal & R6 & $1 / 48$ & $\mathrm{~V}_{1}$ & 4.28 & 1.24 & Triplet \\
\hline $\mathrm{CrO}_{3}$ bridging & R6 & $1 / 48$ & $V_{2}$ & 6.59 & 3.56 & Singlet antiferromagnetic \\
\hline
\end{tabular}

Table S2. Formation energies of oxygen vacancies, $E_{v a c}$, in oxides. Energies referred to $O$ instead of $1 / 2 \mathrm{O}_{2 ;}\left(E_{\mathrm{vac}}(\mathrm{O})=\mathrm{E}_{\mathrm{vac}}(1 / 2 \mathrm{O} 2)+3.03\right)$ are also displayed. Results are listed in decreasing order (selecting the concentration of defects indicated by an asterisk * that corresponds to supercells as defined in Table 2. All our calculations and those from literature are made with the same methodology (PBE/PAW) except those from refs [18] and [20] made with PW91/US-PP. The type of vacancy indicates the coordination of the missing $\mathrm{O}$ atom. The results from ref [66] use a $(3 \times 3 \times 3)$ supercell (concentration: 1/108). For reducible oxides, the spin state is that obtained using the Hubbard correction (U from Table 3). For $\mathrm{Ta}_{2} \mathrm{O}_{5}$, there are many $\mathrm{O}$ sites; removing a 3-fold coordinated $\mathrm{O}$ in the horizontal layer either leads to a reconstruction forming a new bond (reconstructed) or decreases the coordination of the adjacent tantalum atoms including $\left(V_{3 \mathrm{~h} 1}\right)$ or not $\left(\mathrm{V}_{3 \mathrm{~h} 2}\right)$ a 7 -fold coordinated Ta atom - see text and ref.[70]. 
Fractional Coordinates of the different bulk metal oxides

The geometry files (format POSCAR/CONTCAR VASP files) used in the present work can be downloaded from:

https://sites.google.com/site/calatayudantonino/k/oxides 


\section{References}

1. Carrasco J, Gomes JRB, Illas F (2004) Theoretical study of bulk and surface oxygen and aluminum vacancies in alpha- $\mathrm{Al}_{2} \mathrm{O}_{3}$. Physical Review $\mathrm{B} 69$ (6):13. doi:064116

10.1103/PhysRevB.69.064116

2. Oleinik II, Tsymbal EY, Pettifor DG (2000) Structural and electronic properties of $\mathrm{Co} / \mathrm{Al}_{2} \mathrm{O}_{3} / \mathrm{Co}$ magnetic tunnel junction from first principles. Physical Review B 62 (6):3952-3959

3. Hossein Asghar Rahnamaye Alibad SRG (2011) Structural and Spin Polarization Effects of $\mathrm{Cr}$, Fe and $\mathrm{Ti}$ Elements on Electronical Properties of $\alpha-\mathrm{Al}_{2} \mathrm{O}_{3}$ by First Principle Calculations. Journal of Modern Physics, 2:158-161

4. French RH, Müllejans H, Jones DJ (1998) Optical Properties of Aluminum Oxide: Determined from Vacuum Ultraviolet and Electron Energy-Loss Spectroscopies. Journal of the American Ceramic Society 81 (10):2549-2557. doi:10.1111/j.1151-2916.1998.tb02660.x

5. French RH (1990) Electronic band structure of $\mathrm{Al}_{2} \mathrm{O}_{3}$, with comparison to AION and AIN. Journal of the American Ceramic Society 73 (3):477-489. doi:10.1111/j.1151-2916.1990.tb06541.x

6. French RH, Jones DJ, Loughin S (1994) Interband Electronic Structure of $\alpha$-Alumina up to $2167 \mathrm{~K}$. Journal of the American Ceramic Society 77 (2):412-422. doi:10.1111/j.1151-2916.1994.tb07009.x

7. Tews W, Gründler R (1982) Electron-Energy-Loss Spectroscopy of Different $\mathrm{Al}_{2} \mathrm{O}_{3}$ Modifications. I. Energy Loss Function, Dielectric Function, Oscillator Strength Sum Rule and the Quantity $\in 2 \mathrm{E}$. Physica Status Solidi (b) 109 (1):255-264. doi:10.1002/pssb.2221090128

8. Laughlin RB (1980) Optical absorption edge of $\mathrm{SiO}_{2}$. Physical Review B 22 (6):3021-3029

9. Xu Y-n, Ching WY (1991) Electronic and optical properties of all polymorphic forms of silicon dioxide. Physical Review B 44 (20):11048-11059

10. Evrard R, Trukhin AN (1982) Photoelectric properties and the energy gap of $\mathrm{SiO}_{2}$. Physical Review B 25 (6):4102-4105

11. Kantorovich LN, Holender JM, Gillan MJ (1995) The energetics and electronic structure of defective and irregular surfaces on MgO. Surface Science 343 (3):221-239

12. Zhukovskii YF, Kotomin EA, Evarestov RA, Ellis DE (2007) Periodic models in quantum chemical Simulations of F Centers in crystalline metal oxides. International Journal of Quantum Chemistry 107 (14):2956-2985. doi:10.1002/qua.21483

13. Xu Y-N, Gu Z-Q, Ching WY (1997) Electronic, structural, and optical properties of crystalline yttria. Phys Rev B 56:23

14. Badehian HA, Salehi H, Ghoohestani M (2013) First-Principles Study of Elastic, Structural, Electronic, Thermodynamical, and Optical Properties of $\mathrm{Yttria}\left(\mathrm{Y}_{2} \mathrm{O}_{3}\right)$ Ceramic in Cubic Phase. Journal of the American Ceramic Society 96 (6):1832-1840. doi:10.1111/jace.12259

15. Sah RE (2011) Silicon Nitride, Silicon Dioxide, and Emerging Dielectrics 11, vol 35. The Electrochemical Society,

16. Mehandru R, Luo B, Kim J, Ren F, Gila BP, Onstine AH, Abernathy CR, Pearton SJ, Gotthold D, Birkhahn R, Peres B, Fitch R, Gillespie J, Jenkins T, Sewell J, Via D, Crespo A (2003) AIGaN/GaN metal-oxide--semiconductor high electron mobility transistors using $\mathrm{Sc}_{2} \mathrm{O}_{3}$ as the gate oxide and surface passivation. Applied Physics Letters 82 (15):2530-2532

17. Tippins $\mathrm{HH}$ (1965) Optical absorption and photoconductivity in band edge of beta- $\mathrm{Ga}_{2} \mathrm{O}_{3}$. Physical Review A 140 (1):A316-A319

18. Foster AS, Gejo FL, Shluger AL, Nieminen RM (2002) Vacancy and interstitial defects in hafnia. Physical Review B 65 (17):174117. doi:174117 10.1103/PhysRevB.65.174117

19. Balog M, Schieber M, Michman M, Patai S (1977) Chemical vapor deposition and characterization of $\mathrm{HfO}_{2}$ films from organo-hafnium compounds. Thin Solid Films 41 (3):247-259. doi:http://dx.doi.org/10.1016/0040-6090(77)90312-1

20. Foster AS, Sulimov VB, Gejo FL, Shluger AL, Nieminen RM (2001) Structure and electrical levels of point defects in monoclinic zirconia. Physical Review B 64 (22):224108. doi:224108 10.1103/PhysRevB.64.224108 
21. Kralik B, Chang EK, Louie SG (1998) Structural properties and quasiparticle band structure of zirconia. Physical Review B 57 (12):7027-7036

22. Robertson J (2006) High dielectric constant gate oxides for metal oxide Si transistors. Reports on Progress in Physics 69 (2):327-396. doi:10.1088/0034-4885/69/2/r02

23. Dash LK, Vast N, Baranek P, Cheynet MC, Reining L (2004) Electronic structure and electron energy-loss spectroscopy of $\mathrm{ZrO}_{2}$ zirconia. Physical Review B 70 (24):245116. doi:245116

10.1103/PhysRevB.70.245116

24. Varley JB, Weber JR, Janotti A, Van de Walle CG (2010) Oxygen vacancies and donor impurities in beta- $\mathrm{Ga}_{2} \mathrm{O}_{3}$. Applied Physics Letters 97 (14):142106. doi:142106 10.1063/1.3499306

25. Orita $\mathrm{M}$, Ohta $\mathrm{H}$, Hirano $\mathrm{M}$, Hosono $\mathrm{H}$ (2000) Deep-ultraviolet transparent conductive beta- $\mathrm{Ga}_{2} \mathrm{O}_{3}$ thin films. Applied Physics Letters 77 (25):4166-4168

26. Passlack M, Schubert EF, Hobson WS, Hong M, Moriya N, Chu SNG, Konstadinidis K, Mannaerts JP, Schnoes ML, Zydzik GJ (1995) $\mathrm{Ga}_{2} \mathrm{O}_{3}$ films for electronic and optoelectronic applications. Journal of Applied Physics 77 (2):686-693

27. Yamaguchi K (2004) First principles study on electronic structure of beta-Ga2O3. Solid State Communications 131 (12):739-744. doi:10.1016/j.ssc.2004.07.030

28. Thulin L, Guerra J (2008) Calculations of strain-modified anatase $\mathrm{TiO}_{2}$ band structures. Physical Review B 77 (19):195112. doi:10.1103/PhysRevB.77.195112

29. Diebold U (2003) The surface science of titanium dioxide. Surface Science Reports 48 (5-8):53-229

30. Yang ZX, Woo TK, Baudin M, Hermansson K (2004) Atomic and electronic structure of unreduced and reduced $\mathrm{CeO}_{2}$ surfaces: A first-principles study. Journal of Chemical Physics 120 (16):7741-7749. doi:10.1063/1.1688316

31. Clima S, Pourtois G, Van Elshocht S, De Gendt S, Heyns MM, Wouters DJ, Kittl JA (2009) Dielectric Response of $\mathrm{Ta}_{2} \mathrm{O}_{5}, \mathrm{NbTaO}_{5}$ and $\mathrm{Nb}_{2} \mathrm{O}_{5}$ from First-Principles Investigations. ECS Transactions 19 (2):729-737

32. Darlinski A, Halbritter J (1987) Angle-resolved XPS studies of oxides at NbN, NbC, and Nb surfaces. Surface and Interface Analysis 10 (5):223-237. doi:10.1002/sia.740100502

33. Mishra KC, Johnson KH, Schmidt PC (1995) Electronic structure of antimony-doped tin oxide. Physical Review B 51 (20):13972-13976

34. Bouzoubaa A, Markovits A, Calatayud M, Minot C (2005) Comparison of the reduction of metal oxide surfaces: $\mathrm{TiO}_{2}$-anatase, $\mathrm{TiO}_{2}$-rutile and $\mathrm{SnO}_{2}$-rutile. Surface Science 583 (1):107-117. doi:10.1016/j.susc.2005.03.029

35. Silva AFd, Pepe I, Persson C, Souza_de_Almeida J, Moyses_Araujo C, Ahuja R, Johansson B, An CY, Guo J-H (2004) Optical Properties of Oxide Compounds $\mathrm{PbO}, \mathrm{SnO}_{2}$ and $\mathrm{TiO}_{2}$. Physica Scripta Vol T109:180-183

36. Singh AK, Janotti A, Scheffler M, Van de Walle CG (2008) Sources of Electrical Conductivity in SnO2. Physical Review Letters 101 (5):055502

37. Rantala TT, Rantala TS, Lantto V (2000) Electronic structure of $\mathrm{SnO}_{2}$ (110) surface. Materials Science in Semiconductor Processing 3 (1-2):103-107

38. Landolt-Börnstein (ed) (1982) Numerical Data and Functional Relationship in Science and Technology, vol III/17. New Series. Springer, Berlin

39. Janotti A, Varley JB, Rinke P, Umezawa N, Kresse G, Van de Walle CG (2010) Hybrid functional studies of the oxygen vacancy in $\mathrm{TiO}_{2}$. Physical Review B 81 (8):085212. doi:085212 10.1103/PhysRevB.81.085212

40. $\mathrm{Gu}$ T, et al., (2009) First-principles simulations on bulk $\mathrm{Ta}_{2} \mathrm{O}_{5}$ and $\mathrm{Cu} / \mathrm{Ta}_{2} \mathrm{O}_{5} / \mathrm{Pt}$ heterojunction: Electronic structures and transport properties. J Appl Phys 106:03713

41. Ivanov MV, Perevalov TV, Aliev VS, Gritsenko VA, Kaichev VV (2011) Electronic structure of delta $\mathrm{Ta}_{2} \mathrm{O}_{5}$ with oxygen vacancy: ab initio calculations and comparison with experiment. Journal of Applied Physics 110 (2):024115-024115

42. Helali Z, Calatayud M, Minot $C$ (2014) Novel delta- $\mathrm{Ta}_{2} \mathrm{O}_{5}$ structure obtained from DFT calculations. J Phys Chem C 118:13652-13658 
43. Chun W-J, Ishikawa A, Fujisawa $\mathrm{H}$, Takata $\mathrm{T}$, Kondo JN, Hara M, Kawai M, Matsumoto $\mathrm{Y}$, Domen $\mathrm{K}$ (2003) Conduction and Valence Band Positions of $\mathrm{Ta}_{2} \mathrm{O}_{5}, \mathrm{TaON}$, and $\mathrm{Ta}_{3} \mathrm{~N}_{5}$ by UPS and Electrochemical Methods. The Journal of Physical Chemistry B 107 (8):1798-1803. doi:10.1021/jp027593f

44. Tepehan FZ, Ghodsi FE, Ozer N, Tepehan GG (1997) Determination of optical properties of amorphous Ta2O5 films deposited by spin- and dip-coating methods. Solar Energy Materials and Solar Cells 46 (4):311-321

45. Li Y, Wu LM, Li JQ, Zhang YF, Huang X, Zhou LX (1999) Study on the band structures of defective and irregular surfaces on MgO. Chinese Journal of Structural Chemistry 18 (3):218-226

46. Shvets VA, Aliev VS, Gritsenko DV, Shaimeev SS, Fedosenko EV, Rykhlitski SV, Atuchin VV, Gritsenko VA, Tapilin VM, Wong H (2008) Electronic structure and charge transport properties of amorphous Ta2O5 films. Journal of Non-Crystalline Solids 354 (26):3025-3033. doi:http://dx.doi.org/10.1016/j.jnoncrysol.2007.12.013

47. Scanlon DO, Walsh A, Morgan BJ, Watson GW (2008) An ab initio study of reduction of $\mathrm{V}_{2} \mathrm{O}_{5}$ through the formation of oxygen vacancies and Li intercalation. Journal of Physical Chemistry C 112 (26):9903-9911. doi:10.1021/jp711334f

48. Zimmermann R, Steiner P, Claessen R, Reinert F, Hüfner S, Blaha P, Dufek P (1999) Electronic structure of 3d-transition-metal oxides: on-site Coulomb repulsion versus covalency. Journal of Physics: Condensed Matter 11 (7):1657

49. Kaid MA (2006) Characterization of electrochromic vanadium pentoxide thin films prepared by spray pyrolysis. Egypt J Solids 29 (2):273-291

50. Madelung O, Rössler U, Schulz $\mathrm{M}(2014) \mathrm{V}_{2} \mathrm{O}_{5}$ : energy gap: cluster calculations data. In: LandoltBörnstein - Group III Condensed Matter 41D. Springer Materials. doi:10.1007/10681735_346

51. Van Hieu N, Lichtman D (1981) Bandgap radiation induced photodesorption from $\mathrm{V}_{2} \mathrm{O}_{5}$ powder and vanadium oxide surfaces. Journal of Vacuum Science and Technology 18 (1):49-53

52. Hanafi ZM, Ismail FM, Mohamed AK (1996) X-ray Photoelectron Spectroscopy of Chromium Trioxide and some of its Suboxides. Zeitschrift für Physikalische Chemie, vol 194. doi:10.1524/zpch.1996.194.Part_1.061

53. Khilla MA, Hanna AA (1981) Electrical properties of semiconductor materials. Chromium trioxide. Thermochimica Acta 51 (2):335-341. doi:http://dx.doi.org/10.1016/0040-6031(81)85171-4

54. Wang L, Maxisch T, Ceder G (2006) Oxidation energies of transition metal oxides within the GGA+U framework. Physical Review B 73 (19):195107

55. Zhai HJ, Li S, Dixon DA, Wang LS (2008) Probing the electronic and structural properties of chromium oxide clusters $\left(\mathrm{CrO}_{3}\right)(n)(-)$ and $\left(\mathrm{CrO}_{3}\right)(\mathrm{n})(\mathrm{n}=1-5)$ : Photoelectron Spectroscopy and density functional calculations. Journal of the American Chemical Society 130 (15):5167-5177. doi:10.1021/ja077984d

56. Bullett DW (1983) Bulk and surface electron states in $\mathrm{WO}_{3}$ and tungsten bronzes. Journal of Physics C: Solid State Physics 16 (11):2197

57. De Wijs GA, De Boer PK, De Groot RAK, G. (1999) Anomalous behavior of the semiconducting gap in WO3 from first-principles calculations. Physical Review B 59 (4):2684-2693

58. Koffyberg FP, Dwight K, Wold A (1979) Interband transitions of semiconducting oxides determined from photoelectrolysis spectra. Solid State Communications 30 (7):433-437

59. Hollinger G, Pertosa P, Doumerc JP, Himpsel FJ, Reihl B (1985) Metal-nonmetal transition in tungsten bronzes: A photoemission study. Physical Review B 32 (4):1987-1991

60. Kaczkowski J (2012) Electronic Structure of Some Wurtzite Semiconductors: Hybrid Functionals vs. Ab Initio Many Body Calculations. Acta Physica Polonica A 121:1142

61. Usuda M, Hamada N, Kotani T, van Schilfgaarde M (2002) All-electron GW calculation based on the LAPW method: Application to wurtzite ZnO. Physical Review B 66 (12):125101

62. Massidda S, Resta R, Posternak M, Baldereschi A (1995) Polarization and dynamical charge of ZnO within different one-particle schemes. Physical Review B 52 (24):R16977-R16980 
63. Oshikiri M, Aryasetiawan F (2000) Quasiparticle Energy Calculations on II(Zn)-VI(O, S, Se) and III (Al,Ga)-V(N) Semiconductors in the Wurtzite Structure. Journal of the Physical Society of Japan 69 (7):2113-2120. doi:10.1143/JPSJ.69.2113

64. Muscat J, Wander A, Harrison NM (2001) On the prediction of band gaps from hybrid functional theory. Chemical Physics Letters 342 (3-4):397-401. doi:http://dx.doi.org/10.1016/S00092614(01)00616-9

65. Safa O. Kasap PC (2006) Springer handbook of electronic and photonic materials.

66. Carrasco J, Lopez N, Illas F (2004) First principles analysis of the stability and diffusion of oxygen vacancies in metal oxides. Physical Review Letters 93 (22):225502. doi:225502 10.1103/PhysRevLett.93.225502

67. Ganduglia-Pirovano MV, Hofmann A, Sauer J (2007) Oxygen vacancies in transition metal and rare earth oxides: Current state of understanding and remaining challenges. Surface Science Reports 62 (6):219-270. doi:10.1016/j.surfrep.2007.03.002

68. Jiang Y, Adams JB, van Schilfgaarde M, Sharma R, Crozier PA (2005) Theoretical study of environmental dependence of oxygen vacancy formation in $\mathrm{CeO}_{2}$. Applied Physics Letters 87 (14):141917. doi:141917 10.1063/1.2084324

69. Chatten R, Chadwick AV, Rougier A, Lindan PJD (2005) The Oxygen Vacancy in Crystal Phases of $W_{3}$. The Journal of Physical Chemistry B 109 (8):3146-3156. doi:10.1021/jp045655r

70. Helali Z, Calatayud M, Minot C (2014) Novel Delta- $\mathrm{Ta}_{2} \mathrm{O}_{5}$ Structure Obtained from DFT Calculations. J Phys Chem C 118 (25):13652-13658. doi:10.1021/jp503088h 